\title{
Separating bathymetric data representing multiscale rhythmic bed forms: A geostatistical and spectral method compared
}

\author{
Thaiënne A. G. P. van Dijk, ${ }^{1,2,3}$ Roderik C. Lindenbergh, ${ }^{4}$ and Paul J. P. Egberts ${ }^{2}$ \\ Received 20 November 2007; revised 4 September 2008; accepted 18 September 2008; published 24 December 2008.
}

[1] The superimposition of rhythmic bed forms of different spatial scales is a common and natural phenomenon on sandy seabeds. The dynamics of such seabeds may interfere with different offshore activities and are therefore of interest to both scientists and offshore developers. State-of-the-art echo sounding accuracy allows for the analysis of bed form dynamics on unprecedented spatial and temporal scales. However, the superimposition of bed forms complicates the automated determination of morphodynamic parameters of individual bed form components. In this research we present the extension and comparison of two well-known, automated signal-processing methods for the 1-D and 2-D separation of bathymetric data derived from multibeam echo soundings into different components that each represents a bed form of a particular length scale. One method uses geostatistical filtering, and the other uses a Fourier decomposition of the bathymetric data. The application of both methods in two case studies of the North Sea shows that both methods are successful and that results correspond well. For example, megaripples up to $0.83 \mathrm{~m}$ height could be separated from $1.49-2.28 \mathrm{~m}$ high sand waves, and regionally averaged lengths and heights of sand waves, as calculated in either method, differ only $0.42-8.2 \%$ between methods. The obtained sand wave migration rates differ $7-11 \%$ between methods. The resulting morphometric and morphodynamic bed form quantification contributes to studies of empirical behavior and morphodynamic model validation and is valuable in risk assessments of offshore human activities.

Citation: van Dijk, T. A. G. P., R. C. Lindenbergh, and P. J. P. Egberts (2008), Separating bathymetric data representing multiscale rhythmic bed forms: A geostatistical and spectral method compared, J. Geophys. Res., 113, F04017, doi:10.1029/2007JF000950.

\section{Introduction}

[2] Rhythmic bed forms are widespread on shallow sandy seabeds and river beds. The superimposition of bed forms of different spatial scales, each changing at a different temporal scale, causes a complex dynamic behavior of the bed. On the North Seafloor, for example, sand waves with wavelengths between 100 and $800 \mathrm{~m}$ and wave heights in the order of meters are reported to migrate measurable distances on time scales of years [Van Dijk and Kleinhans, 2005; Van Dijk et al., 2006], whereas superimposed megaripples, which are a factor 10 smaller, observably migrate on the scale of days [Knaapen, 2005; Knaapen et al., 2004; Wever and Stender, 2000], or even of hours [Idier et al., 2002]. However, it is only partly understood how sand waves and megaripples interact dynamically at the seabed.

\footnotetext{
${ }^{1}$ Deltares, Utrecht, Netherlands.

${ }^{2}$ Geological Survey of the Netherlands, TNO Built Environment and Geosciences, Utrecht, Netherlands.

${ }^{3}$ Department of Water Engineering and Management, University of Twente, Enschede, Netherlands.

${ }^{4}$ Delft Institute of Earth Observation and Space Systems, Delft University of Technology, Delft, Netherlands.

Copyright 2008 by the American Geophysical Union. 0148-0227/08/2007JF000950\$09.00
}

[3] That such interaction exists is indicated empirically by several authors: the occurrence, size, orientation [Lindenbergh, 2004; Van Dijk, 2002; Van Dijk and Kleinhans, 2005] and the migration rate [Knaapen et al., 2004] of megaripples is observed to vary systematically with their relative location on the underlying sand waves. Idier et al. [2004] showed in a numerical morphodynamic model that variable flow conditions over sand waves cause megaripples to grow only on those parts of sand waves where the bed shear stress is sufficiently large. Since the dynamic behavior of megaripples appears to be controlled by sand waves and since megaripples are much more mobile than sand waves [Cullen, 2005; Knaapen et al., 2004], and thus easier to observe on short time scales, we hypothesize that the morphodynamics of megaripples are a good proxy for the dynamics of sand waves. For this purpose, the quantification of individual bed form dynamics is crucial. Correctly separated compound bed forms allow for a more accurate calculation of the shape and migration rate of bed forms of different scales. Consecutively, obtained bed form parameter values can serve as input for simulation models that link morphology to local hydrodynamic conditions. Such approach may lead to a better insight in to what extent megaripples interfere with the migration of sand waves.

[4] The dynamics of individual bed forms are important to both scientists and offshore developers. For example, modeled variations in the boundary layer thickness over 
sand waves and their bed roughness affect the bed shear stress and hence the sediment transport [Idier et al., 2004; Soulsby, 1997]. Also, sand banks and sand waves affect tidal flow directions [e.g., Elias et al., 2003; Van de Meene, 1994] and interfere with surface waves in shallow water [Van Dijk and Kleinhans, 2005]. Megaripples, too, despite their apparent small dimensions, affect the hydrodynamics by damping surface waves and therewith affect sediment transport [Cherlet et al., 2007]. Understanding these processes is imperative for maintaining the natural coastal defense of countries such as the Netherlands. Farther offshore, sand banks and sand waves are of interest to the marine aggregate industry. From an engineering point of view, mobile bed forms interfere with offshore constructions. For example, height differences caused by migrating sand waves may affect the stability and productivity of offshore wind turbines and have caused free spans of pipelines [Morelissen et al., 2003; Santoro et al., 2004]. Investigating the local dynamics of seabeds in anticipation on selecting suitable construction sites proves to be important in lowering the risks (thereby lowering insurance costs) as well as mitigating the impacts on offshore constructions. From a managing point of view, sand waves in shallow areas may form a danger to navigation, for example, in the shipping lane approaching the harbor of Rotterdam, the Netherlands. Empirical knowledge on the regional dynamics of sand waves and megaripples leads to more efficient survey planning and dredging strategies for those authorities that are either charting the seafloor areas or maintaining critical navigation depths [Cullen, 2005; Dorst, 2004; Pluymaekers et al., 2007; Wüst, 2004].

[5] A wide range of process-based morphodynamic models explains the generation and evolution of bed forms. Hulscher [1996] demonstrated that sand waves are generated by residual vertical circulation cells in which sand is transported toward the sand wave crests. Extended models show that sand wave migration is caused by a tidally induced residual flow [Németh, 2003; Németh et al., 2002] and higher tidal constituents [Besio et al., 2003, 2004]. Németh et al. [2007] refine the explanation of sand wave evolution with sensitivity tests using an idealized model. The occurrence and dimensions (esp. wavelength) of sand waves have been predicted in models by Hulscher and Van den Brink [2001], Van der Veen et al. [2006], Besio et al. [2006] and Cherlet et al. [2007] and are shown to be dependent on, among others, water depth, tidal regime and sediment grain size. Other models simulate the effect of existing bed forms on the boundary layer flow conditions [Idier et al., 2004]. Although it is essential to validate these theoretical models with empirical data [e.g., Németh, 2003], this has only been done summarily [e.g., Cherlet et al., 2007; Németh et al., 2007], because of the scarcity of reliable empirical analysis results.

[6] With the arrival of multibeam echo sounding (MBES), the state-of-the-art technique in which many depth observations are obtained simultaneously in a wide swath below the ship [FitzGerald and Knight, 2005; Lurton, 2002], and in combination with the differential Global Positioning System (dGPS), the vertical and horizontal accuracy and horizontal resolution are adequate for reliable empirical morphodynamic investigations of both sand waves and megaripples together. The limited horizontal resolution of traditional single beam echo sounding, in which soundings are only obtained vertically below the ship, does not allow for the calculation of migration rates of sand waves [e.g., Lanckneus and De Moor, 1991; see also Németh, 2003; Németh et al., 2002; Terwindt, 1971], let alone of megaripples. In contrast, modern MBES results in observational densities of several to tens of soundings per square meter in shallow seas as the North Sea.

[7] To date, the geometry and especially the migration of sand waves have been determined manually from maps (Besio et al. [2004], V. Van Lancker (personal communication, 2007, about data given by Cherlet et al. [2007]), Lanckneus and De Moor [1991], and Van Dijk and Kleinhans [2005]) or by simplified calculations for geometry only [e.g., Santoro et al., 2004]. Analyzing the large, digital data sets obtained with MBES require a new, objective and automated analysis approach. However, the superimposition of bed forms of differential mobility complicates the automated analysis of individual bed form parameters, such as wavelength, wave height, asymmetry and crest orientation, and dynamic parameters, such as wavelength and wave height variations and migration rate. It is therefore necessary to develop an automated method that separates the bathymetric data into bed forms of different spatial scales.

[8] Several approaches exist for the automatic separation of dense surveying data into subsets with certain predescribed properties. For the purpose of separating vegetation points from real terrain points in airborne laser scanning data [Sithole and Vosselman, 2004], notably the robust interpolation method is designed [Kraus and Pfeifer, 1998]. This method iteratively determines a surface that runs in a suited way between the two sets of points by adapting the interpolating weight of each point accordingly in each iteration, for instance by using a geostatistical approach. It has been shown that this method can also be used to remove outliers in MBES data [Bottelier et al., 2005]. A classic application of using spectral methods in the geospatial domain is the representation of the Earth's gravitational field by a series of spherical harmonics [Heiskanen and Moritz, 1967]. Both geostatistical and spectral methods have been applied to detect and describe periodic morphological features from gridded topographic maps [Mulla, 1988]. The author concludes that the spectral method is favorable in describing periodic features, whereas the geostatistical approach is the only method capable of identifying the orientation and correlation scale of relatively small nonperiodic features. Fourier series are normally used to approximate one-dimensional harmonic time series [e.g., Oppenheim et al., 1997] and were previously applied to describe aeolian bed forms [Stam, 1994]. Curvatures, here used for locating crest and trough lines, was also used in automated landform analyses, then often referred to as "ridges and valleys" [e.g., Cazals et al., 2005; Rana, 2006].

[9] Closer to our field, Knaapen [2005] previously used a low-pass filter to remove megaripples from sand waves as noise in order to estimate sand wave dimensions and migration rates, but his value of sand wave migration seems to be overestimated by a factor 3 for one of our cases (Egmond). He provides a general estimation of the influence of the input data accuracy, but does not account for errors that were incorporated by the method itself when validating the method. Dorst et al. [2006] recently presented a defor- 


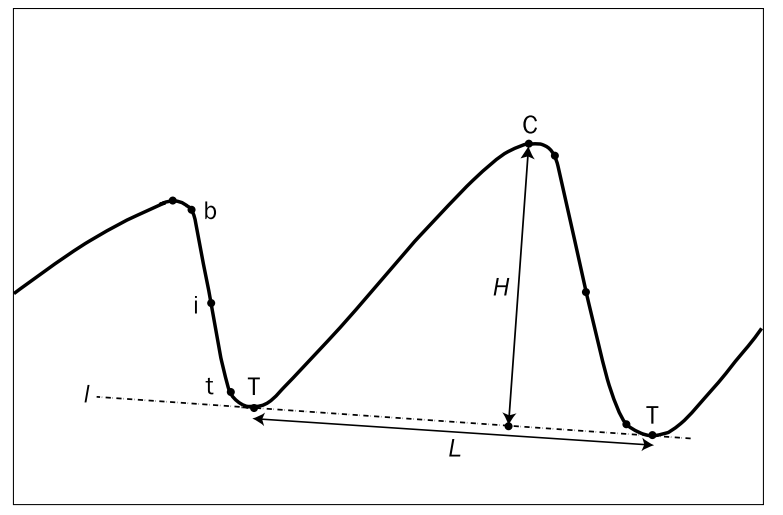

Figure 1. Definition of the morphologic parameters wavelength and height and characteristic morphologic points of bed forms, the crest point, $\mathrm{C}$; trough point, $\mathrm{T}$; inflection point of the lee side, $i$; brink point, $b$; and toe point, $t$.

mation analysis method for the estimation of sand wave dynamics, in which statistical hypotheses of ideal bed form models are tested on gridded echo soundings (cell size $50 \mathrm{~m}$ ). Herein, the complexity of the bed is built up in three levels, but the morphology remains idealized (e.g., by assuming planes for underlying sloping trends and perfect sinusoids for sand waves) and does not reach the complexity level of megaripples. These two existing methods both exclude an analysis of megaripples and both rely on certain a priori assumptions of the seafloor morphology. What is still missing in our point of view is an approach that focuses purely on the bathymetric signal contained in the available echo soundings.

[10] In this paper, we present and evaluate two methods, newly extended for the automated separation of echo sounding-based bathymetric data into bed forms of different spatial scales, which are subsequently applied in the morphodynamic investigation of compound bed forms. The first method is factorial Kriging, a sophisticated geostatistical data analysis method [Goovaerts, 1997], and the second method is a Fourier analysis, whereby the original signal is decomposed in a series of sinusoids. From these separated signals, morphometric and morphodynamic parameters of individual bed forms of different scales can be calculated objectively. Both methods are tested on the same MBES data of two sites in the North Sea and the results are compared and discussed, complete with uncertainty and sensitivity analyses. We hereby concentrate on the separation of sand waves and megaripples. The results of this work will contribute to the understanding of individual bed form dynamics in various environments, such as coastal, marine, estuary and river environments, and will lead to applications such as a seabed dynamics map of the North Sea.

[11] In section 2, we define the bed form parameters and describe both methods. In section 3, we present the separation results of both methods, supported by accuracy levels and applied to the same data sets of two case studies of different sand wave fields in the North Sea. In section 4, we determine individual bed form parameters from the separated signals. In the two final sections of the paper, we discuss method accuracies and sensitivities, flexibility and efficiency, and state the concluding remarks and wider implications.

\section{Description of the Two Bed Form Separation Methods}

\subsection{Bed Form Parameter Definitions}

[12] The bed form orientation, or strike, is the average angle in degrees from UTM north (over east) of the bed form crest lines. Several definitions of sand wave dimension parameters are used in the literature. In this paper, we define the sand wavelength, $L$, as the length of the base line segment connecting two consecutive trough points on the smoothed sand wave profile normal to the strike, see Figure 1. The sand wave height, $H$, is the length of the line segment, perpendicular to the base line segment, that connects the base line, $l$, to the sand wave crest point. The term amplitude is reserved for the original physical definition of the distance between the midpoint and maximum extent of a wave function. The megaripple length and height are defined analogously. Characteristic morphologic points of bed forms, which are used in this paper, are indicated in Figure 1.

\subsection{Geostatistical Separation Method: Factorial Kriging}

[13] The geostatistical 2-D filter method for separating an original signal into a sand wave component and a megaripple component first applies a variogram analysis to determine the direction-dependent variability of the bathymetric signal. The directional variograms are used to decompose the bathymetric signal into a sand wave and mega ripple component by means of factorial Kriging.

\subsubsection{Variograms and Sand Wave Orientation}

[14] The presence of sand waves causes a different variability in the seafloor topography in different directions. One way to determine the dominant direction of the sand wave crest is to perform a variability analysis [Dorst, 2004]. For this purpose, variabilities in depth $\left(z_{i}-z_{j}\right)^{2}$ are computed for pairs of depth observations $\left(x_{i}, y_{i}, z_{i}\right)$ and $\left(x_{j}, y_{j}, z_{j}\right)$. The results are grouped with respect to the difference in length and direction of the positional difference vectors $\left(x_{i}-x_{j} ; y_{i}-y_{j}\right)$. When averaging the results per difference class, the anisotropic, experimental variogram is obtained [Goovaerts, 1997]. The sand wave orientation is obtained by determining the direction of minimal variability. Figure 2 shows two directional variograms, one parallel to the sand wave crest (bottom curve) and one perpendicular to the crests (top curve). In Figure 2, the dots represent experimental variograms and the continuous lines are positive definite variogram functions fitted to the experimental variograms. While fitting, mostly a choice is made between three classes of variogram functions: the exponential, the spherical and the Gaussian class [Goovaerts, 1997]. The principal difference between the classes is in their derivative at the origin and at the smoothness behavior this implies: Gaussian functions have zero derivatives, while the derivatives of the other two classes are always negative. Therefore the Gaussian class produces relatively smooth surfaces, at the cost of being computationally less stable.

[15] Commonly used parameters in variogram fitting are the range, the distance after which the maximal variability of the signal is reached, the sill, i.e., the value of the 


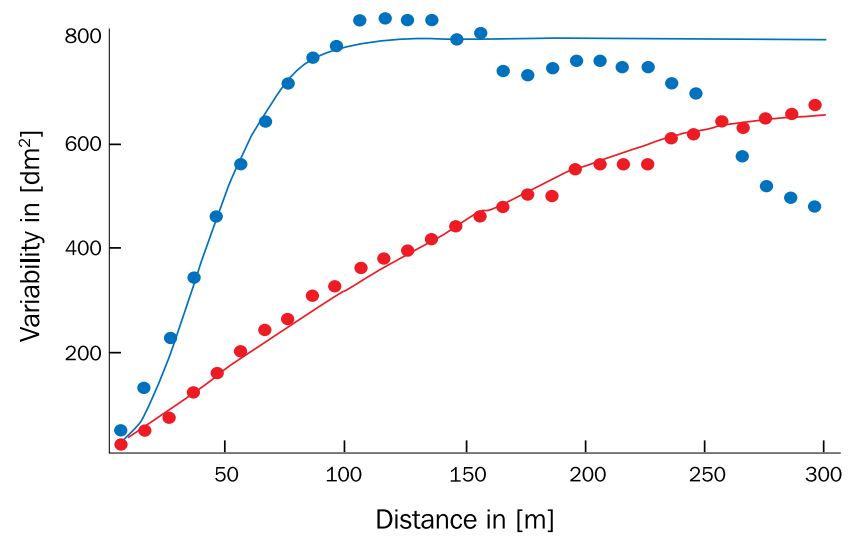

Figure 2. Directional variograms in the directions parallel (bottom curve) and perpendicular (top curve) to the sand wave crests. The periodicity in the top dotted line represents the periodicity of sand waves.

maximal variability, and the nugget, the microscale variability that appears in the variogram as the $y$ axis intercept. In Figure 2, the variability in the direction perpendicular to the crests first reaches a sill value of around $800 \mathrm{dm}^{2}$ at $100 \mathrm{~m}$ and then decreases again. This decrease coincides with the periodicity of the sand wave signal. The poor fit at larger distances does not cause any problems in the following interpolation step because of the negligible weight of observations at larger distances.

\subsubsection{Ordinary Kriging}

[16] The Ordinary Kriging method determines the Best Linear Unbiased Predictor (BLUP) for a depth $\hat{z}_{0}=\sum_{i=1}^{n} w_{i} z_{i}$ at location $p_{0}$ from depth observations $z_{1}, \ldots, z_{n}$, at locations $p_{1}, \ldots, p_{n}$, given a covariance function $\operatorname{cov}(\mathbf{h}): \mathbf{R}^{2} \rightarrow \mathbf{R}$, depending on the difference vector, $\mathbf{h}_{i j}$, between two observations $p_{i}$ and $p_{j}$ [Goovaerts, 1997]. This depth prediction $\hat{z}_{0}$ is optimal in the sense that it minimizes the expected error variance, given the unbiased condition. It can be shown that this optimal solution for the weights is obtained by solving the ordinary Kriging system $C_{n} \cdot w_{n}=d_{n}$, with

$$
C_{n}=\left(\begin{array}{cccc}
C_{11} & \cdots & C_{1 n} & 1 \\
\vdots & \ddots & \vdots & \vdots \\
C_{n 1} & \cdots & C_{n n} & 1 \\
1 & \cdots & 1 & 0
\end{array}\right), \quad d_{n}=\left(\begin{array}{c}
C_{10} \\
\vdots \\
C_{n 0} \\
1
\end{array}\right), \quad w_{n}=\left(\begin{array}{c}
w_{1} \\
\vdots \\
w_{n} \\
\mu
\end{array}\right)
$$

[17] Here, $C_{n}$, denotes the redundancy matrix filled with covariances $C_{i j}=\operatorname{cov}\left(\mathbf{h}_{i j}\right)$ between the observations. The proximity vector, $d_{n}$, contains the covariances $C_{i 0}=\operatorname{cov}\left(\mathbf{h}_{i 0}\right)$ between the prediction location $p_{0}$ and the observations. Solving the system is always possible, given a positive definite covariance function, and the unique solution gives the weights $w_{1}, \ldots, w_{n}$, corresponding to the BLUP. To ensure that the found solution is indeed unbiased, an additional condition that the weights sum up to one, is necessary. This extra condition is added to the system by means of a Lagrange multiplier $\mu$. This extra condition to ensure unbiasedness is not necessary if the mean depth is known. In this case, local deviations of the mean are predicted using a simplified version of System (equation (1)), the
Simple Kriging system. On the other hand, an extension of System (equation (1)) may be necessary if the seafloor contains a trend: parameters describing such trend can be estimated simultaneously by adding more Lagrange parameters; this method is referred to as Universal Kriging. For a more extensive overview of the alternative Kriging systems available, the reader is referred to textbooks as [Goovaerts, 1997] and [Wackernagel, 2003]. Note that solving the Kriging system not only results in a predicted depth $\hat{z}_{0}$, but also in a formal error variance value $\hat{e}_{o}$. This error variance reflects the proximity of the observations, with respect to the covariance function: the stronger the correlation between the prediction location and the observations, the lower the error variance. Note that the error variance does not depend on the actual depth values of the observations.

\subsubsection{Incorporating Anisotropy}

[18] Assuming second-order stationarity, variograms and covariance functions are directly related, and the correspondence is given in the variogram by $\gamma(h)=\sigma^{2}-\operatorname{cov}(\mathbf{h})$, where $\sigma^{2}$ is the sill. From Figure 2 it is clear that the variogram value, and thus the covariance value between two positions, depends on the direction of the difference vector between the positions. Therefore we use a 2-D covariance function for the Kriging system that combines the two extreme directional covariance functions, $\operatorname{cov}_{C}$, in the direction $\alpha_{C}$ parallel to the crests, and $\operatorname{cov}_{P}$, in the direction $\alpha_{P}$ perpendicular to the crest (compare Figure 2). For this purpose we decompose the difference vector $\mathbf{h}=\left(h_{x}, h_{y}\right)$ between two positions in a crest component $h_{C}$ and a perpendicular component $h_{P}$, that is, we use $\operatorname{cov}\left(h_{x}, h_{y}\right)=$ $1 / 2\left(\operatorname{cov}_{C}\left(h_{C}\right)+\operatorname{cov}_{P}\left(h_{P}\right)\right)$ with

$$
\left(\begin{array}{l}
h_{C} \\
h_{P}
\end{array}\right)=\left(\begin{array}{cc}
\cos \alpha_{C} & \cos \alpha_{P} \\
\sin \alpha_{C} & \sin \alpha_{P}
\end{array}\right)^{-1} \cdot\left(\begin{array}{l}
h_{x} \\
h_{y}
\end{array}\right),
$$

to fill the redundancy matrix and the proximity factor.

\subsubsection{Separating Spatial Components}

[19] The bathymetric signal $Z$ contains a sand wave component $Z_{S}(x, y)$ and a megaripple component $Z_{M}(x, y)$. It moreover contains a component $Z_{N}(x, y)$ representing noise and possibly signals from smaller bed forms. Therefore we can write

$$
Z(x, y)=Z_{S}(x, y)+Z_{M}(x, y)+Z_{N}(x, y) .
$$

Separating the sand wave component from the smaller components is achieved by predicting $\hat{Z}_{S}(x, y)$ at the observation locations. For this purpose we use a slightly adapted version of Ordinary Kriging. The variability in $z$ values due to sand waves can be determined by using a subset of the original data set, such that its resolution is high enough to represent the sand wave signal, but low enough to neglect most of the smaller components. In this way we obtain the long-range variograms as shown in Figure 2. Kriging with a long range means that observations on long distance still will contribute in the prediction. The sand wave component can be emphasized even more by filtering the nugget, $N$ [Goovaerts, 1997; Wackernagel, 2003]: if the nugget value $N$ is present only in the diagonal elements of the redundancy matrix but not in the proximity vector, it will be filtered out and we will obtain $\hat{Z}_{S}(x, y)$ when solving 
(a)

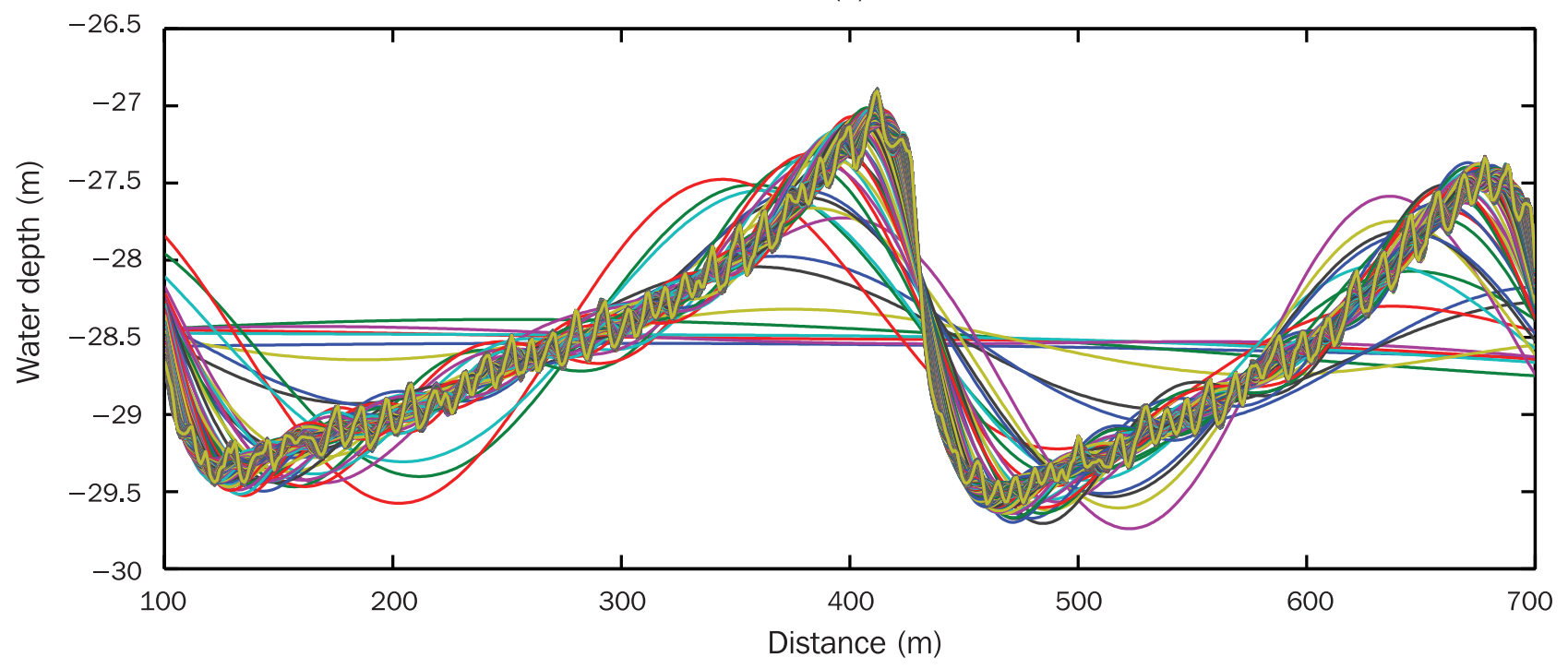

(b)
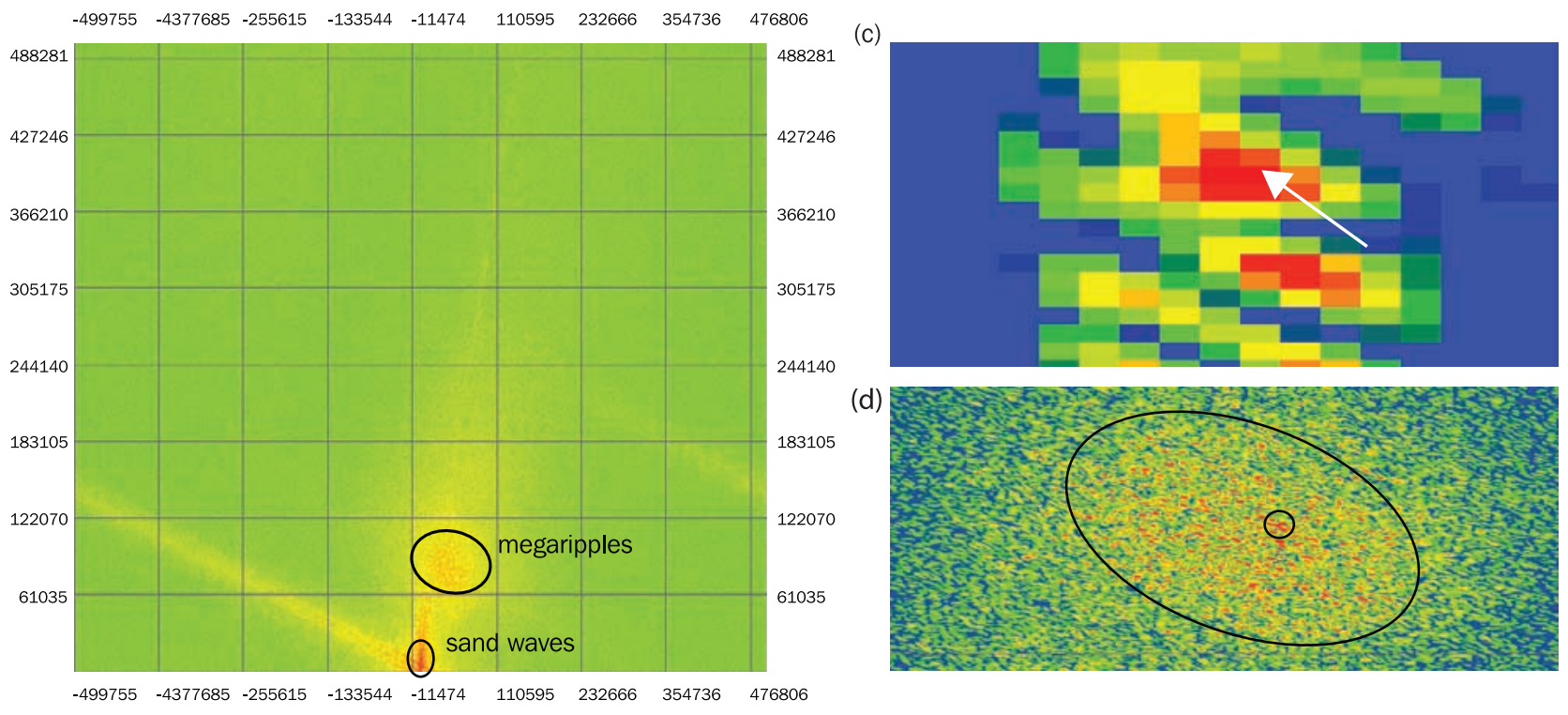

Figure 3. (a) Cumulative constituents of the Fourier analysis (zoomed in), showing three groups of constituents that each represent a bed form type when summed: a near-horizontal large-scaled topography, sand waves, and megaripples. (b) A 2-D power plot, with directional wave numbers, $k$, on the $x$ and $y$ axes. Two zooms from the 2-D power plot: (c) The concentrated results for the sand waves, opposed to (d) the more diffuse megaripple results.

the Kriging system. Moreover, the remaining signal, that is the residual, gives an estimation of the megaripple component including signal and measurement noise. This procedure of separating spatial components within the Kriging paradigm is generally referred to as factorial Kriging [Goovaerts, 1997]. Note that it is in principle possible to add more components to equation (3), for example a component $Z_{L}$ corresponding to sand banks. A possible signal part corresponding to a sand bank component can be found by applying the method for isolating the sand wave component on an appropriate, larger, spatial scale. In general, components can be found iteratively by starting of with the largest component, subtracting the estimation corresponding to this component from the signal and continue for the next component using the remaining signal.

\subsubsection{Determination of Crest and Trough Lines}

[20] Given the sand wave components, the crest and trough lines are easily obtained by determining the maxima (crests) and minima (troughs) along all vertical profiles through the gridded sand wave representation. Note that in this particular case the vertical or north-south direction is approximately perpendicular to the sand wave crest orientation. As a result of the removal of the strongly varying megaripple component, a smooth sand wave signal remains. Therefore the maxima and minima are found by determining extreme values within a search range, where the range length is bounded above by the sand wavelength. 


\subsubsection{Uncertainty Calculations of the Kriging Method}

[21] The robustness of determining the bed form orientation via the variogram analysis is assessed by considering the quality of fit of the used variogram models and by considering the spread in variability as a function of direction. The smoothing process is monitored both visually, by plotting both the smoothed and input profiles together, and quantitatively, by calculating the error distributions of differences between the input data and the Kriging approximation, i.e., the residual megaripple signal, for both the profiles (1-D) and surfaces (2-D). Quality measures are the symmetry and standard deviation (in $\mathrm{m}$ ) of these distributions and the maxima of the errors. Lack of symmetry in the distribution of the residual differences is an indication for systematic biases that on their side indicate a not optimal smoothing process. The calculation of crest and trough point (CT) locations on the smoothed curves is approximate and is restricted to the grid points of the used grid. The evaluation is done by visual inspection of the CT positions on contour plots of both the smoothed surfaces and input grids.

\subsection{Fourier Analysis}

[22] A Fourier analysis is very useful for analyzing superimposed rhythmic bed forms, such as compound sand waves, because it breaks down a signal into a series of constituent sinusoids of different amplitudes and frequencies. Here, we apply one- and two-dimensional discrete Fourier analyses on MBES data to, respectively, separate an original signal of compound bed forms into sequences of individual bed form types and to obtain the characteristic orientation and plan view dynamics of the bed forms.

[23] For the 2-D Fourier analysis, the input is an interpolated grid of the measured MBES data, or surface. The surfaces were obtained with a simple Kriging algorithm at 1 by $1 \mathrm{~m}$ cells (for accuracy calculations for each step, see section 2.3.3.). Despite the high density and uniform distribution of the measurements, the Kriging algorithm was chosen, on the basis of best precision performances in preanalysis assessments of Average, Median and Kriging interpolation results. The input for the 1-D analysis is a profile, i.e., a sampled signal $(\mathrm{dx} \approx 1 \mathrm{~m})$ from the surface. 2.3.1. Separation of the Compound Signal

[24] If a one-dimensional sampled signal on a finite length interval is sampled with $N$ sample values $f_{j}, 0 \leq$ $j<N$, then these values can be expressed by the Fourier series [Press et al., 2002]:

$$
f_{j}=\frac{1}{N} \sum_{k=0}^{N-1} F_{k} e^{-2 \pi i j k / N}
$$

where $F_{k}$ are the Fourier coefficients calculated by the discrete Fourier transform. A plot of the constituent sinusoids may show different groups of frequencies, which each represent a different bed form type. For example, Figure 3a shows three clear groups of frequencies, representing, when summed, a sand bank, sand waves and megaripples. These groups can be separated by multiple truncation (i.e., low-pass filtering) of the original Fourier series (equation (4)) at certain frequencies that correspond to wavelengths between two bed form wavelengths. The cutoff frequency is determined by choosing a value that minimizes the number of identified crest and trough points other than those of sand waves, and thus separates the megaripples successfully, but still approaches the sand wave morphology well (in this paper referred to as "optimal truncation"). The determination of the cutoff frequencies was aided with a power versus wavelength plot, or periodogram, to ascertain that the cutoff frequencies were chosen in the nondominant frequency domain. The resulting truncated series are Fourier approximations, or smoothed curves, of the separated signals for the bed form types with the larger wavelengths. The subtraction of these approximations from the original bathymetric input signal results in the residual signal of the smallest bed form type.

[25] By applying a 2-D Fourier transform, the orientation of bed forms is obtained as follows. The 2-D power versus wave number plot of the gridded data (Figures $3 b-3 d$ ) reveals the dominant wave number, $k$, in both the $x$ and $y$ direction, as the cell of the highest power, ideally as one point. Bed form wavelengths in both directions can be calculated by $\lambda=1 / k$. The slopes of the lines through the points of dominant wave numbers and the origin of the plot provide the characteristic orientations of the bed form types in question. For example, in Figures $3 b-3 d$, cells with maximum power that correspond to the wavelengths and orientations of sand waves (dark), occur in a condensed zone or even a single cell (arrow in Figure 3c). In the case of megaripples, the 2-D power plot displays a diffuse cloud of cells with medium high power (lighter), due to the smaller bed form height and the large variability of wavelengths and orientations of megaripples over the lengths of sand waves [Van Dijk and Kleinhans, 2005].

[26] A present extension of the Fourier method includes the identification of three levels of spatial scales, allowing for not only the separation of megaripples from sand waves, but also the separation of sand waves from a large-scale underlying morphology, for example sand banks.

\subsubsection{Determination of Crest and Trough Lines}

[27] In the Fourier method, the locations of crest and trough lines are determined through calculation of the minimal and maximal curvatures at each point of the bed form surface. These computations involve first- and secondorder derivatives, requiring a smoothed surface [e.g., Cazals et al., 2005].

[28] The smoothing of the surface was done by truncating the discrete 2-D Fourier representation of the surface. Out of other filter options, such as the Savitzky-Golay [Press et al., 2002], we chose for a Fourier filter, on the basis of the rigorous physical description of a surface. Two optional filters were examined: (1) a low-pass filter, which truncates the Fourier series at a chosen cutoff frequency, and (2) a $n$ th-order Butterworth filter [Oppenheim et al., 1997], which has a more gentle filtering profile, of which the sharpness can be set by choosing the order. This latter filter performed best as it suppresses ringing artifacts, the Gibbs phenomenon. Because of satisfying results, no other filter options were considered.

[29] The curvature calculations [e.g., Gray, 1997], are applied on the smoothed surface, denoted by $S=S(x, y)$. To clarify the concept of curvature, consider a plane through a point on the surface $S$ containing the (e.g., upward pointing) normal vector and a unit tangential vector. The intersection 
(a)

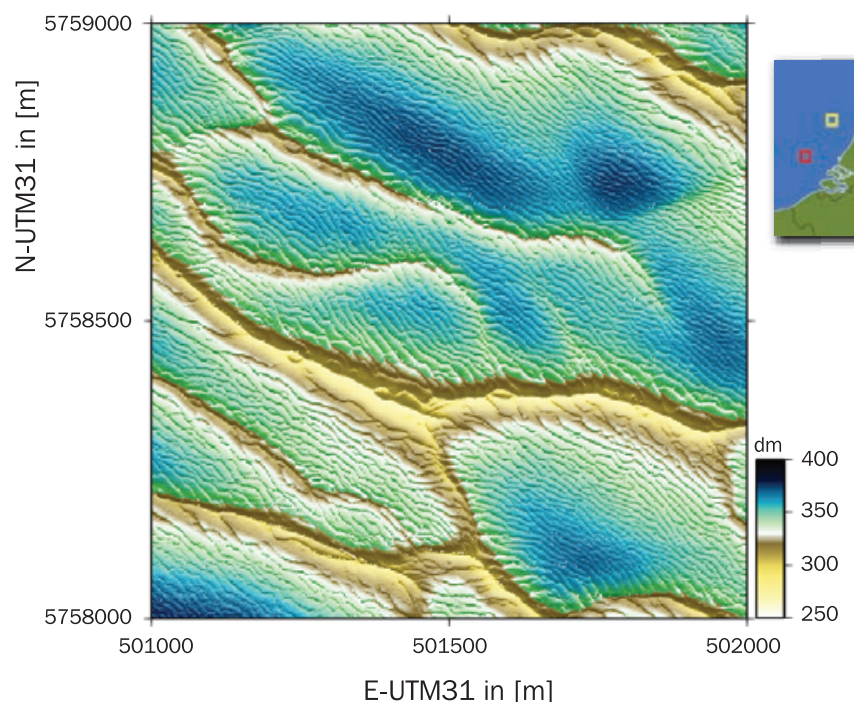

(b)

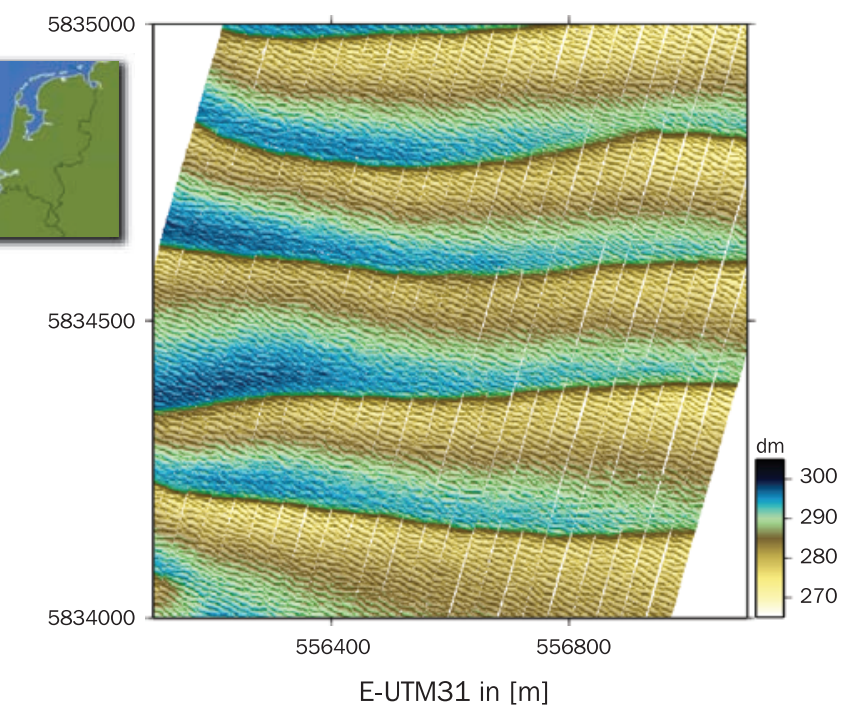

Figure 4. Interpolated MBES images of $1 \mathrm{~km}^{2}$ areas, showing sand waves and megaripples. (a) Rotterdam survey of 2002 and (b) Egmond survey of March 2001. Depths are given in decimeters to MSL. The locations of Rotterdam (bottom square) and Egmond (top square) are indicated on the inset map.

of this plane with the surface $S$ results in a plane curve for which a curvature can be defined. The curvature of a plane curve is a measure of the sharpness of the bend of the curve. For any plane curve constructed in the described way a curvature can be computed. The maximum (or first) and minimum (or second) principal curvatures $\kappa_{1}$ and $\kappa_{2}$ are defined as the maximum and minimum curvatures in view of all plane curves. The associated unit tangential vectors are called the principal directions and denoted by $v_{1}$ and $v_{2}$. Principal curvatures and directions can conveniently be calculated using the theorem that states that $\kappa_{1}$ and $\kappa_{2}$, are the eigenvalues of the symmetric Weingarten matrix with the corresponding orthonormal eigenvectors $v_{1}$ and $v_{2}$ [Cazals et al., 2005].

[30] It is assumed that the extreme values of curvature on the smoothed surface occur at the crest and trough lines. A crest line is expected to be locally orthogonal to the first principal direction (the direction with largest curvature) and has a maximal value along this direction. Therefore a crest point is defined as a point $(x, y, S(x, y))$ for which the directional derivative of $S$ along the first principal direction $v_{1}$ vanishes, and the first principal curvature $\kappa_{1}>0$ is sufficiently large. (The directional derivative of $S$ along the vector $v_{1}$ is calculated as $\nabla S \cdot v_{1}$, that is, the inner product of the gradient of $S$ in $(x, y)$ and the vector $v_{1}$.) Likewise, a trough point is defined as a point for which the directional derivative of $S$ along the second principal direction $v_{2}$ equals zero and the second principal curvature $\kappa_{2}<0$ is sufficiently small.

2.3.3. Uncertainty Calculations of the Fourier Method

[31] In the Fourier method, each step of the procedure is evaluated by an uncertainty calculation. The vertical accuracy of the MBES measurements in water depths used in the cases in this paper is about $0.2 \mathrm{~m}$. The interpolation quality of the input grids is defined in terms of reproducibility rather than by the discrepancy between the gridded $z$ values and the measured $z$ values in that cell. Hereto, grids were resampled to the exact locations of the original data points. The standard deviation (in $\mathrm{m}$ ) of the distribution of differences between resampled $z$ values and the original MBES measurements at each point is a measure for the reproducibility. Vertical differences up to a few dm's are acceptable, with the main criterion being the vertical measuring accuracy of the MBES data. A measure of the success of representation of the real seabed is quantified by the variances of observations within one grid cell. Uncertainties of the bed form orientations follow from the calculated range in angles within the cell of highest power (Figure 3b); for the more diffuse zone of high power corresponding to megaripple frequencies, the range in orientation is determined by angles corresponding to the edges of the "cloud" (see section 2.3.1).

[32] Monitoring of the smoothing process is done as described in section 2.2.6. In the Fourier method, the calculation of CT locations on the smoothed curves is exact. The evaluation is done as described in section 2.2.6, with the additional inspection using three-dimensional surface plots.

\section{Bed Form Separation Results for Both Methods}

[33] Both methods of bed form separation are applied in two case studies in the North Sea. One site is the Rotterdam approach zone, $70 \mathrm{~km}$ offshore from the coast near Rotterdam, the Netherlands (Figure $4 \mathrm{a}$ ), covering $1 \mathrm{~km}^{2}$, of which an almost yearly time series exists between 1992 and 2003. The Rotterdam site comprises rather irregular sand waves of different wavelengths and heights, covered by megaripples.

[34] The other site is a sand wavefield $50 \mathrm{~km}$ offshore Egmond aan Zee, the Netherlands (Figure 4b), which covers an area of 1 by $2.5 \mathrm{~km}$ and of which 5 data sets exist between March 2001 and September 2002. At this site, sand waves are more regular, both in height and alignment, and also covered by megaripples. 
(a)

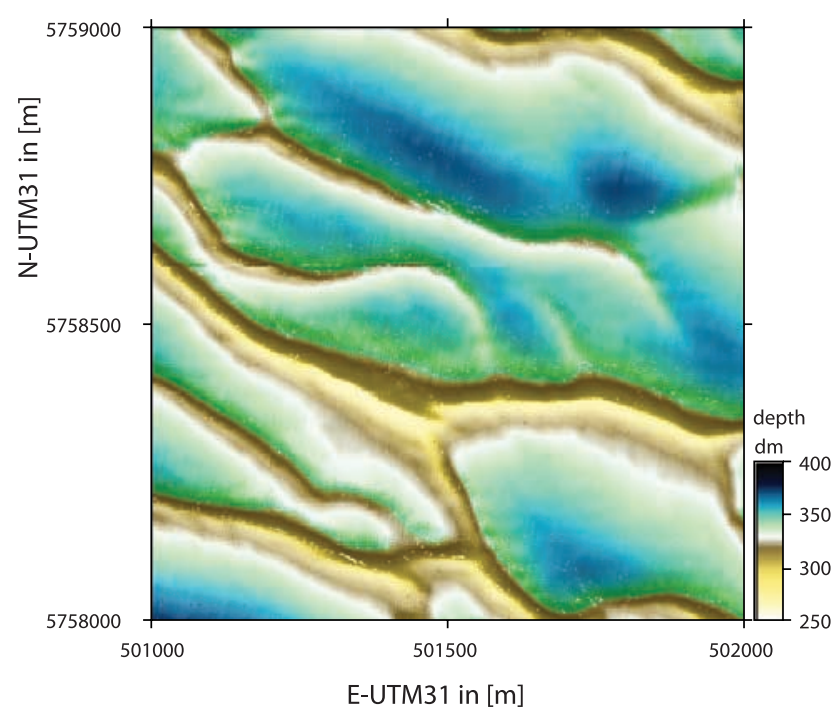

(b)

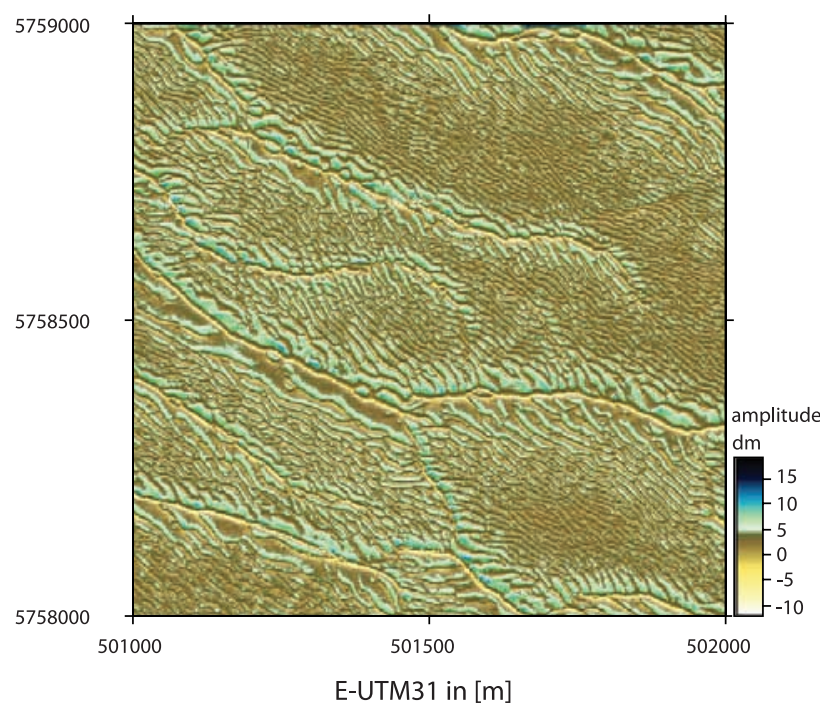

Figure 5. Two-dimensional separation results of the geostatistical filtering method for the Rotterdam data (2002): (a) the separated sand wave signal and (b) the residual megaripple signal.

[35] Separation results of all epochs are taken into account in the interpretations, but merely the 2002 data for Rotterdam and the March 2001 data for Egmond are displayed in the figures in this paper. Both raw MBES data sets have a data density of about 3 observations per $\mathrm{m}^{2}$. For both case studies and in both methods, no separate noise component is taken into account. That is, in all results, the megaripple component still includes possible measurement and interpolation uncertainties and smaller bed forms such as ripples.

\subsection{Case 1: Bed Form Separation Results, Rotterdam Area}

[36] In the geostatistical method, when comparing variograms in different directions, an average crest orientation of $\alpha_{C}=113^{\circ}$ was found, which implies a perpendicular direction of $\alpha_{P}=23^{\circ}$. For both extreme variograms, depicted in Figure 2, the sill value was set at $800 \mathrm{dm}^{2}$ and the nugget at $10 \mathrm{dm}^{2}$. For the crestal variogram (bottom curve), we used a spherical model with a range of $420 \mathrm{~m}$ and for the perpendicular variogram (top curve) a Gaussian model with a range of $50 \mathrm{~m}$.

[37] Figure 5 shows the 2-D geostatistical filtering results, with the separated sand wave signal on the left and the residual megaripple image on the right. This image gives a much clearer representation of the megaripples than Figure 4. Still, the sand wave crests are recognizable, which indicates that near the sand wave crests the smoothing effect of the filter approach is too high. This could be solved by decreasing the nugget value, but tests showed that, in that case, parts of the ripples start to appear in the sand wave signal. A possible solution is to vary the value of the nugget with respect to the local seafloor depth.

[38] In the Fourier method, the characteristic sand wave orientation, $\alpha_{C}$, is $112^{\circ} \pm 5^{\circ}$ and thus the perpendicular direction, $\alpha_{P}$, is $22^{\circ} \pm 5^{\circ}$. These values correspond very well to the results of the geostatistical method. Figure 6 shows (a)

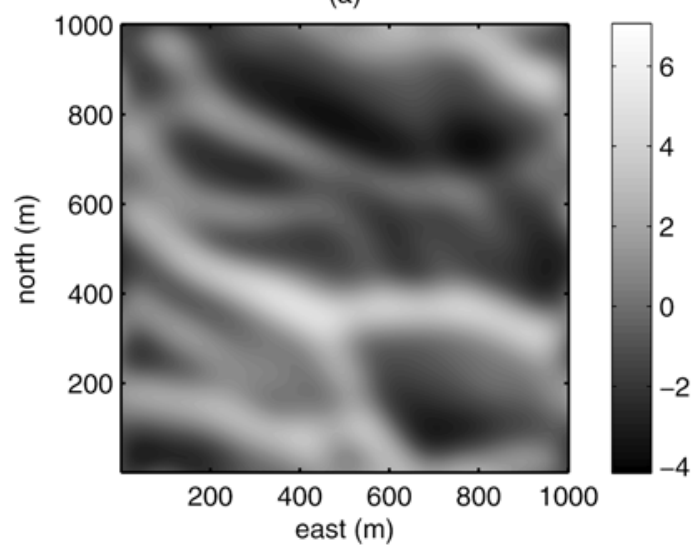

(b)

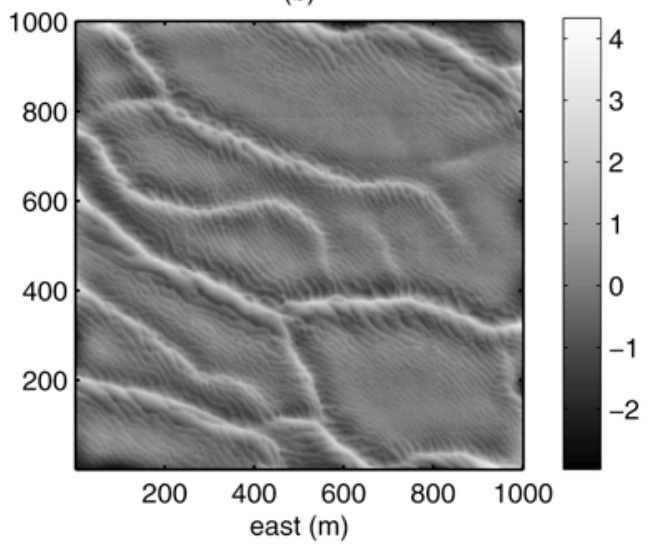

Figure 6. Two-dimensional separation results of the Fourier method of the Rotterdam data (2002): (a) the separated sand wave signal and (b) the residual megaripple signal. Scale bars denote amplitudes in meters. 
(a)

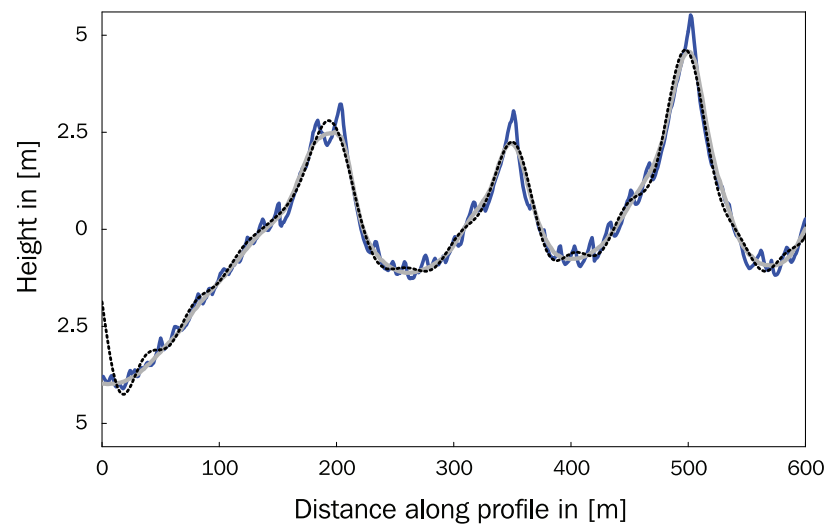

(b)

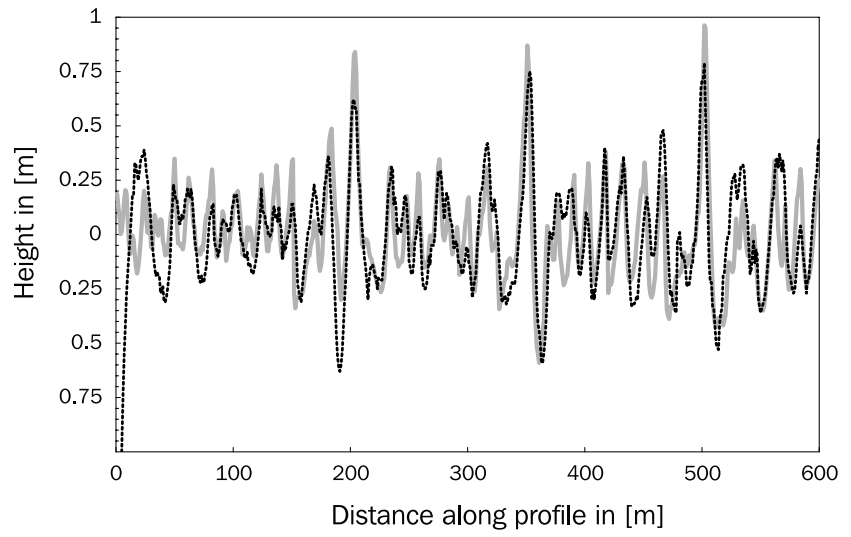

Figure 7. Separation results of both methods for the Rotterdam data (2002) of a profile perpendicular to the sand wave crests. (a) Sand wave signal from the geostatistical method (gray solid) and the Fourier method (black dashed) and real data (spiked line). (b) The megaripple signals of the geostatistical method (gray solid) and the Fourier method (black dashed).

the 2-D filtering results for the Fourier analysis, with the smoothed sand wave signal on the left and the residual megaripple signal on the right. In the 2-D Fourier Butterworth filtering, an optimal truncation was achieved when the order $n=4$ and the truncation is set at 28 frequencies, so that only a vague sand wave signal is recognized in the megaripple signal. However, automated curvature calculations for locating CT lines perform best when the cutoff frequency is 8 , and thus the sand wave signal appears more strongly in the megaripple image.

[39] For Rotterdam, two profiles were examined in the 1-D analyses. The original 1-D compound signals, perpendicular to the calculated orientation of the sand wave crests, were successfully described by a Fourier series with frequencies up to 360 for both profiles (mean $=0.00$; standard deviation $=$ $0.04 \mathrm{~m}$ and $0.02 \mathrm{~m}$ for the western and eastern profile, respectively). For the sand wave approximations, both series were optimally truncated at 28 frequencies, which corresponds to a wavelength of $40 \mathrm{~m}$.

[40] Figure 7 shows the 1-D separation results of the western profile (zoomed) for both methods. Both methods underestimate the sand wave heights (Figure 7a), but the Kriging method slightly more than the Fourier method. The separated sand wave curves of the Kriging method are smoother than those from the Fourier analysis; the latter tuning was chosen, because it improves the estimation of sand wave heights and the remaining perturbations do not interfere with the automated determination of bed form parameters. The Fourier method shows an overshoot at the start of the separated profile, a boundary effect due to the nonperiodicity of the data. We choose to simply ignore the first $25 \mathrm{~m}$ of the Fourier results, so that the overshoot neither affects the separation results nor the determination of sand wave parameters (section 4). Quantitatively, the vertical difference between the smoothed sand wave curves of both methods for the Rotterdam 2002 data shown in Figure $7 \mathrm{a}$, displays a maximum of $0.40 \mathrm{~m}$ (Figure 8 ), which is principally due to different degrees of wave height underestimation. The average difference is $0.12 \mathrm{~m}$, which falls within the measurement accuracy of the input data.
[41] The megaripple signals of both methods show an anomaly near the sand wave crests, due to the underestimation of the sand wave heights. This anomaly was already recognized in the 2-D images, and is clearly visible in Figure $7 \mathrm{~b}$, where the largest peaks in the megaripple signal correspond to the sand wave crests in Figure 7a. This anomaly can also be seen in Figure 9, where the separated curve is plotted with the real data. Figure 9 also shows that the separated megaripples correspond both in size and shape to those in the original compound curve, and that individual megaripples of similar size and shape can be identified in both methods, indicating that the separation of megaripples is successful up to individual bed form level.

[42] In the Fourier method, the vertical interpolation accuracy of the 2002 input grid has a standard deviation of $0.15 \mathrm{~m}$. This value is smaller than the vertical accuracy of the measurements, and is thus acceptable. The distribution of the differences between the smoothed sand wave curves and the original data has a mean of $0.00 \mathrm{~m}$ for both profiles and a standard deviation of $0.27 \mathrm{~m}$ and $0.21 \mathrm{~m}$ for the western and eastern profile, respectively. Larger differences

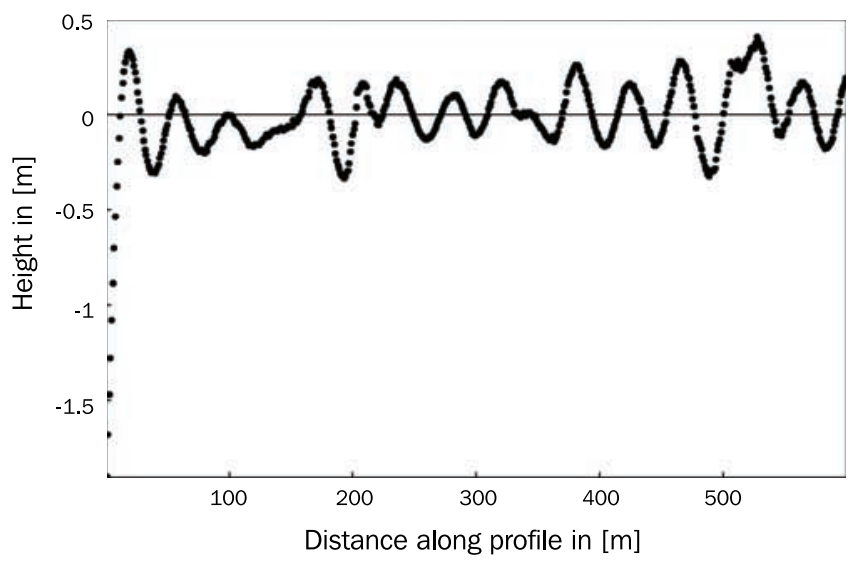

Figure 8. Difference of the smoothed sand wave curves between the Kriging and Fourier methods of the Rotterdam 2002 survey. 
(a)

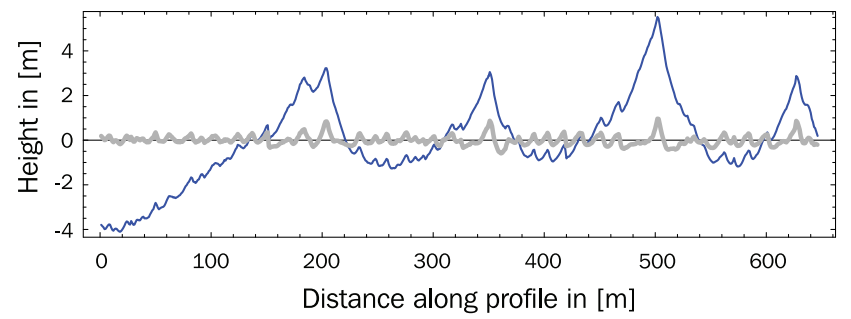

(b)

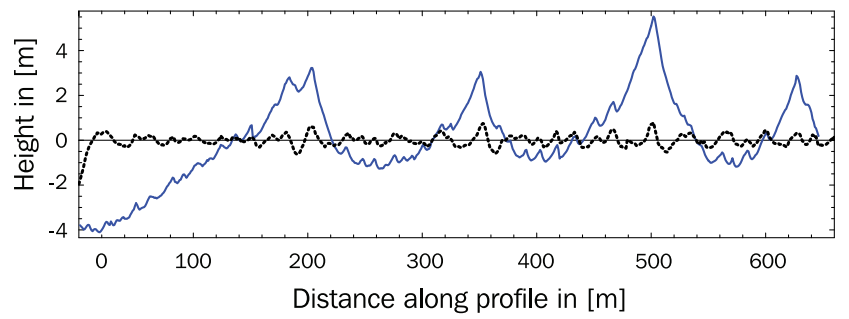

Figure 9. Residual megaripple signal compared to the real data, showing good correspondence in both shape and size of the separated megaripples for (a) the geostatistical method and (b) the Fourier method.

are mainly due to the anomaly at the sand wave crests, and may reach $1 \mathrm{~m}$ for Rotterdam (in some epochs with extremes up to $2.5 \mathrm{~m}$ ), which value exceeds the average megaripple height of $0.18 \mathrm{~m}$, which is $25.9 \%$ of the mean sand wave height at the Rotterdam site.

\subsection{Case 2: Bed Form Separation Results, Egmond Area}

[43] For the Kriging algorithm, a variogram analysis of the Egmond data gave a sand wave crest orientation of $\alpha_{\mathrm{C}}=$ $97^{\circ}$, implying a perpendicular direction of $\alpha_{\mathrm{P}}=7^{\circ}$. For both extreme variograms the sill value was set at $80 \mathrm{dm}^{2}$ and the nugget, again, at $10 \mathrm{dm}^{2}$. For the crestal variogram we used a spherical model with a range of $500 \mathrm{~m}$ and for the perpendicular variogram a Gaussian model with a range of $40 \mathrm{~m}$.

[44] In the Fourier method, the orientation of the Egmond sand waves is $98^{\circ} \pm 1.5^{\circ}$, thus the perpendicular direction is $8^{\circ} \pm 1.5^{\circ}$. The uncertainty here is smaller than in the Rotterdam case, since sand waves are more aligned. This orientation corresponds very well to that obtained in the geostatistical method. The average orientation of the megaripples is $119^{\circ} \pm 9.3^{\circ}$. The large uncertainty, here again, is due to the variable orientation of megaripples over the lengths of sand waves [Van Dijk and Kleinhans, 2005]. Wavelengths and orientations, of about $20^{\circ}$ with respect to the sand wave crests, correspond to earlier manual findings from maps [Van Dijk, 2002; Van Dijk and Kleinhans, 2005]. In the 1-D Fourier analysis, the original signal is described by a Fourier series with frequencies up to 790. For the sand wave approximation, the series is truncated at 62 frequencies, which corresponds to a wavelength of $38 \mathrm{~m}$.

[45] The success of both separation methods is illustrated in Figure 10, where a detail of the separation results perpendicular to the calculated sand wave orientation is plotted together with the original input data. Similar to the Rotterdam case, the geostatistical sand wave signal is smoother than the Fourier signal, but the latter approximates the sand wave heights better. Although the separated megaripple signal shows the same anomaly at the sand wave crests as in the Rotterdam case, the megaripples in both methods are similar in size and shape, also when compared to the original signal (Figure 10), supporting the success of these separation methods on the megaripple scale.

[46] Quantitatively, the maximum difference between the geostatistical and the Fourier sand wave signals for the March 2001 set, along the full $2.5 \mathrm{~km}$ profile, is $0.31 \mathrm{~m}$. Both smoothed sand wave approximations are acceptable in terms of the error standard deviation. In the Fourier method, the standard deviation of the vertical accuracy of the March 2001 input grid is $0.084 \mathrm{~m}$, which is well within the accuracy of the MBES measurements. The distribution of the differences between the smoothed sand wave curve and the real data has a mean of $0.00 \mathrm{~m}$ and a standard deviation of $0.10 \mathrm{~m}$ for both methods, which corresponds to the megaripple heights at this site (see Table 2 in section 4). The maximum difference due to the smoothing is, as before, mainly due to the anomaly at the sand wave crests, and may reach $0.4 \mathrm{~m}$, which is $20.9 \%$ of the average sand wave height. The distribution of differences is slightly skewed (third moment equals 0.31 in the Kriging case) which again reflects the anomaly at the sand wave crests. It should be remarked that the distribution of the differences in this case appears much more regular than in the Rotterdam case, reflecting the more symmetric distribution in the Egmond case.

\section{Determined Parameter Values of Individual Bed Forms}

[47] The main reason for developing bed form separation methods is the need for an objective, automated determination of parameters describing the shape and change of individual bed forms of the different bed form types, including the small perturbations. As a first application of

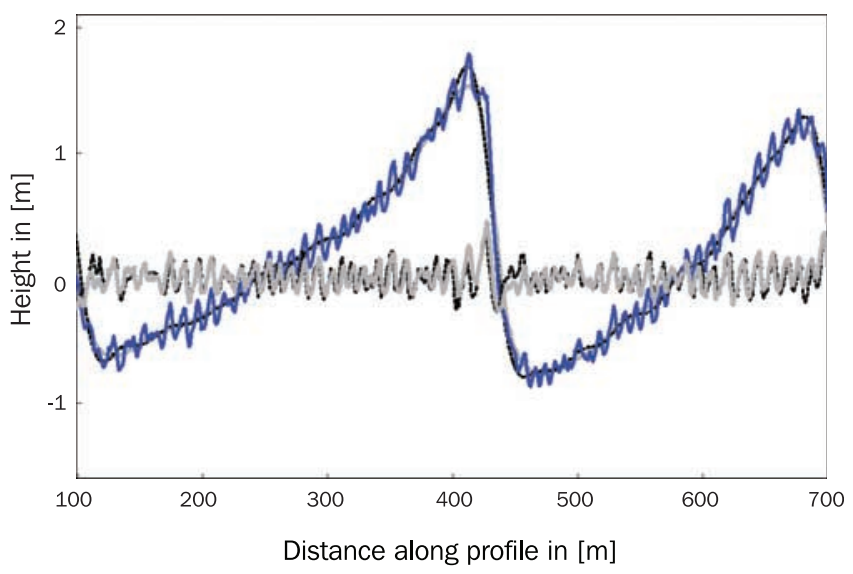

Figure 10. Detail of the separation results of the Egmond March 2001 survey for the geostatistical method (gray solid) and the Fourier method (black dashed), compared to the real data (dark blue solid line). 
Table 1. Sand Wave Sizes ${ }^{\mathrm{a}}$

\begin{tabular}{|c|c|c|c|c|}
\hline & \multicolumn{2}{|c|}{ Geostatistical Method } & \multicolumn{2}{|c|}{ Fourier Analysis } \\
\hline & Wavelength $(\mathrm{m})$ & Wave Height (m) & Wavelength (m) & Wave Height $(\mathrm{m})$ \\
\hline \multicolumn{5}{|c|}{ Rotterdam Sand Wave Data } \\
\hline Minimum & 81 & 1.55 & 72 & 1.69 \\
\hline Maximum & 299 & 6.73 & 288 & 6.85 \\
\hline Average & 161 & 3.79 & 159 & 3.92 \\
\hline \multicolumn{5}{|c|}{ Egmond Sand Wave Data } \\
\hline Minimum & 172 & 1.49 & 171 & 1.67 \\
\hline Maximum & 341 & 2.28 & 337 & 2.46 \\
\hline Average & 238 & 1.84 & 239 & 1.99 \\
\hline
\end{tabular}

${ }^{\text {a }}$ Sand wave geometries are based on eight sand waves (two profiles) in the Rotterdam case and nine sand waves in the Egmond case, using surveys 2002 and March 2001, respectively. Results of other epochs are very similar.

our separation methods, we present the geometry (wavelength and height) of sand waves and megaripples and dynamic parameters (migration) of sand waves along profiles normal to the sand wave crests.

\subsection{Resulting Geometric Bed Form Parameter Values}

[48] Crest and trough points are determined as described in sections 2.2.5 and 2.3.2. Once these points are known, bed form wavelengths and wave heights are determined as defined in section 2.1.

[49] Resulting sand wavelengths and heights are summarized in Table 1. In order to ignore the boundary effects in the Fourier method, the first sand wave in the Rotterdam case was not taken into account. Results of both methods match remarkably well. Calculated average wavelengths for Rotterdam (Table 1 ) only differ $2 \mathrm{~m}$ or $1.2 \%$ of the average wavelength of the geostatistical method, on the basis of 8 sand waves, and for Egmond as little as $1 \mathrm{~m}$ or $0.42 \%$, on the basis of 9 sand waves. Average wave heights calculated in both methods differ $0.13 \mathrm{~m}$ or $3.4 \%$ of the average wave height determined in the geostatistical method for Rotterdam and $0.15 \mathrm{~m}$ or $8.2 \%$ for Egmond. Minimum and maximum lengths and heights are also in very good agreement between methods.

[50] The comparative results for megaripples parameters, as calculated after filtering, between methods are quite poor (Table 2). Profiles analyze large numbers of megaripples and are therefore representative for megaripples in the area. The difference for the average megaripple length in the Rotterdam case is $8.35 \mathrm{~m}$, which is $50.2 \%$ of the geostatistical average wavelength and for heights $0.33 \mathrm{~m}$ or $64.7 \%$ of the geostatistical average wave height, based on the western profile. The length and height ranges for Egmond are in better agreement (Table 2) with differences in wavelength of $31.6 \%$ and of wave height of $33.3 \%$. The large differences in relative errors for megaripple results are explained by methodological differences. First, the different methods and different tuning between methods result in different separated signals for megaripples. Second, locating CT points in the geostatistical method is approximate, whereas in de Fourier method, determining the locations is exact (see sections 2.2.6 and 2.3.3). Third, the number of megaripples included in the analyses is different between methods. In the Rotterdam case, 37 megaripples are used in the geostatistical method and 70 megaripples (including smaller perturbations) in the Fourier method, which is due to the higher precision of the Fourier description of the original input surface and the use of all CT points of the signal. Smaller ripples may in turn be separated from the megaripples by applying an extra truncation. Despite these contrasting results, individual megaripples as derived by both methods are similar in shape. These shapes can also clearly be recognized from the original data profiles.

\subsection{Resulting Dynamic Bed Form Parameter Values}

[51] Both methods automatically return morphologic parameters, from which we determine dynamic parameters of individual bed forms, i.e., the change in wavelength, the change in wave height, the change in horizontal asymmetry, and the horizontal displacement of crest, trough and inflection points from profiles. The geostatistical method calculates a trend on the basis of all time spans, whereas the Fourier method calculates the displacement over the desired period. Table 3 provides the sand wave migration rates for all recent surveys. Between methods, the average migration rates for crest and trough points differ $7.0 \%$ to $11.2 \%$ of the geostatistical average migration rate. In the Fourier average for the Rotterdam case, one outlier was removed. This point

Table 2. Megaripple Sizes

\begin{tabular}{|c|c|c|c|c|}
\hline & \multicolumn{2}{|c|}{ Geostatistical Method } & \multicolumn{2}{|c|}{ Fourier Analysis } \\
\hline & Ripple Length (m) & Ripple Height (m) & Ripple Length (m) & Ripple Height (m) \\
\hline \multicolumn{5}{|c|}{ Rotterdam Megaripple Data } \\
\hline Minimum & 6.00 & 0.12 & 2.00 & 0.005 \\
\hline Maximum & 40.00 & 1.39 & 39.00 & 2.51 \\
\hline Average & 16.65 & 0.51 & 8.30 & 0.18 \\
\hline \multicolumn{5}{|c|}{ Egmond Megaripple Data } \\
\hline Minimum & 6.00 & 0.01 & 1.75 & 0.00019 \\
\hline Maximum & 23.00 & 0.83 & 24.00 & 0.56 \\
\hline Average & 11.70 & 0.24 & 8.00 & 0.16 \\
\hline
\end{tabular}


Table 3. Sand Wave Migration ${ }^{\mathrm{a}}$

\begin{tabular}{|c|c|c|c|c|c|c|}
\hline & \multicolumn{3}{|c|}{ Geostatistical Method } & \multicolumn{3}{|c|}{ Fourier Analysis } \\
\hline & Crest Points & Trough Points & Average CT Points $\left(\mathrm{m} \mathrm{a}^{-1}\right)$ & Crest Points & Trough Points & Average CT Points $\left(\mathrm{m} \mathrm{a}^{-1}\right)$ \\
\hline \multicolumn{7}{|c|}{ Rotterdam 1997-2003 } \\
\hline Average (m) & 3.03 & 0.88 & & 4.13 & 0.63 & \\
\hline Average rate $\left(\mathrm{m} \mathrm{a}^{-1}\right)$ & 0.61 & 0.18 & 0.426 & 0.69 & 0.10 & 0.396 \\
\hline \multicolumn{7}{|c|}{ Egmond March 2001 to September 2002} \\
\hline Average $(\mathrm{m})$ & 0.60 & 4.74 & & 2.25 & 3.45 & \\
\hline Average rate $\left(\mathrm{m} \mathrm{a}^{-1}\right)$ & 0.40 & 3.16 & 1.78 & 1.55 & 2.38 & 1.98 \\
\hline
\end{tabular}

${ }^{\mathrm{a}}$ All displacements are toward NE.

was identified as an outlier, because the crest point represented a broad crest at the bifurcation point of a sand wave and was observed to jump in location in one of the time sets, because of arbitrary (imprecision-driven) crest point identification.

[52] For determining the displacement of megaripples, a more frequent time series is required, in which individual megaripples can be identified in subsequent epochs.

[53] Two-dimensional analyses of crest and trough lines qualify the plan view behavior of sand waves. CT lines for Egmond, determined by the geostatistical method (Figure 11) show a regular pattern of nearly parallel crests and troughs. For the dynamic behavior, a detail of a bifurcation in the northeast corner for all epochs (Figure 11b) reveals that the central ridge is straightening up, as the sand wave moves slightly northward near the bifurcation. Crest and trough lines of the more irregular sand waves at the Rotterdam site, as determined by the 2-D Fourier analysis, are displayed in Figure $12 \mathrm{a}$ in $3-\mathrm{D}$ view. Here too, the dynamic behavior as read from a selection of epochs (Figure 12b), reveals that the displacement is variable along crests and troughs, so that rotation and preferential migration occur. The north-south running ridge of the bifurcation migrates relatively rapidly toward east.

\section{Discussion}

[54] The performances of both methods may be validated by relative errors between mutual method results (parameter values) and between smoothing differences and the average parameter values. The small relative errors of mutual geometric parameter values for sand waves, of less than $8.2 \%$, confirm that the methods are successful in the calculation of parameter values from separated signals. However, the relative errors in sand wave height of 20 $25 \%$ of the average sand wave height, which are due to extreme smoothing differences only, are undesirably large. These anomalies are ascribed to the excessive smoothing near sand wave crests and troughs, which is observed in both methods (section 3 ). The anomaly can be minimized only slightly by different tuning, otherwise the separation becomes poorer. We think that the incorporation of steepness-dependent variability in the horizontal resolution during the smoothing process (i.e., higher resolution at the crests and troughs) will be a solution. At this point in time, we have not tested this, so suggest it to be future work. The large mutual differences of megaripple geometry, of up to $64.7 \%$, are partially explained by the methodological differences (approximate versus exact, see section 4). Furthermore, relatively small wavelengths of megaripples are more easily affected by differences due to the location of grid nodes and search windows. In addition, heights of megaripples are partly within the uncertainty range of the methods, so that differences may become more arbitrary between methods. Nevertheless, since the correct shape of individual megaripples was extracted from the bathymetric signal, we consider the megaripple signal to be a useful estimation of small-scaled bed forms at the seabed.

[55] For the dynamic parameter values of sand waves, migration rate differences of $7-11 \%$ may be partially due to the different calculation in each method (trend versus value, see section 4). Also, migration rates in the Rotterdam and Egmond areas are small and may be close to the accuracy levels of the methods. However, mutual results show exceptionally close agreement. More significantly, mutual migration rates per area are almost the same, whereas those between areas are clearly distinct. This demonstrated value of both methods would be better exhibited when spatial contrasts in migration rates are higher, such as between offshore and coastal areas of the Netherlands, where respective migration rates may be near-static and about $20 \mathrm{~m} / \mathrm{a}$ [Van Dijk and Kleinhans, 2005; Van Dijk et al., 2006]. Migration rates of megaripples could not be determined with the available data sets, because the large time intervals would not allow for reliable identification of individual megaripples in the following data set. This also implies that the hypothesized interaction of megaripple and sand wave dynamics cannot be revealed with these data sets, although the methods would allow for this.

[56] The results presented in this paper are in close agreement with sand wave dimensions obtained manually at the Egmond site [Van Dijk and Kleinhans, 2005]. Van Dijk and Kleinhans [2005] reported a sand wave crest orientation of $91^{\circ}$, a megaripple orientation of $121^{\circ}\left(136^{\circ}\right.$ in sand wave troughs and $110^{\circ}$ near crests), an average sand wavelength of $203 \mathrm{~m}$ and an average sand wave height of $1.79 \mathrm{~m}$, which were determined slightly off the profile that we use here (compare to section 3.1 and Table 1), and a megaripple length of $7 \mathrm{~m}$ (March 2001) and height of $0.4 \mathrm{~m}$ (compare to Table 2). Van Dijk and Kleinhans [2005] determined sand wave migration rates by manually measuring the horizontal displacement of upper and lower lee sides in printed profiles, over the period March 2001 to April 2002. The average migration rate of both upper and lower lee sides comes to $2.00 \mathrm{~m} / \mathrm{a}$ for the manual results, in comparison to $1.69 \mathrm{~m} / \mathrm{a}$ (i.e., March 2001 to April 2002) for the automated Fourier results in this paper. The migration rate for these same Egmond data sets of $6.1 \mathrm{~m} / \mathrm{a}$ over the period 2001-2003 given by Knaapen [2005] seems overestimated, since the close agreement between results of both 
(a)

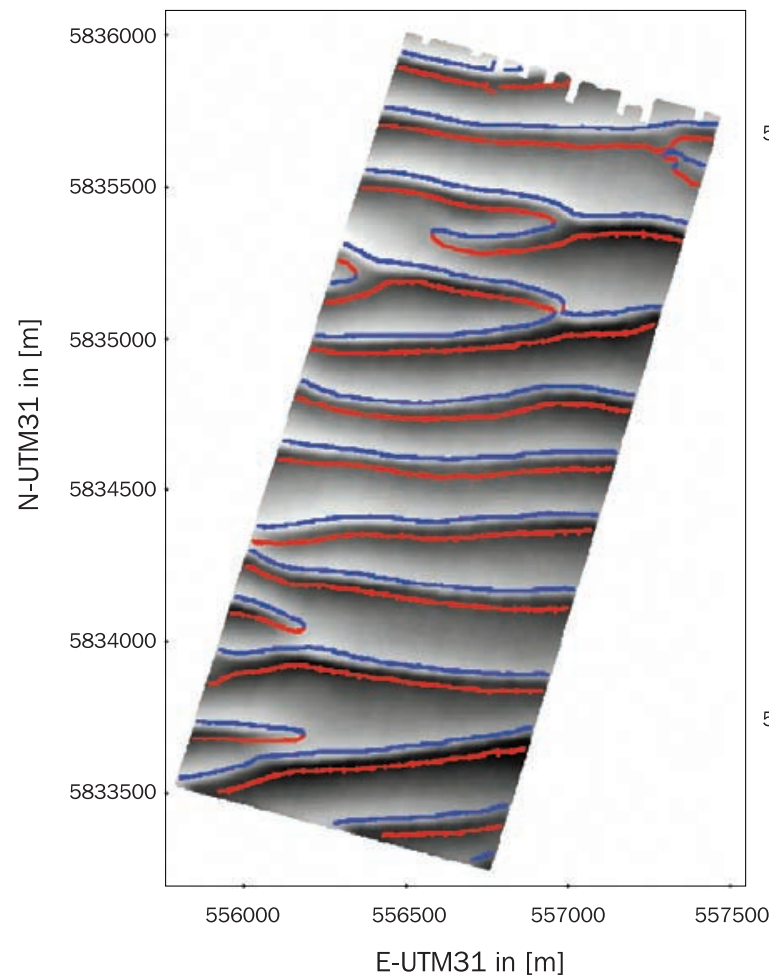

(b)

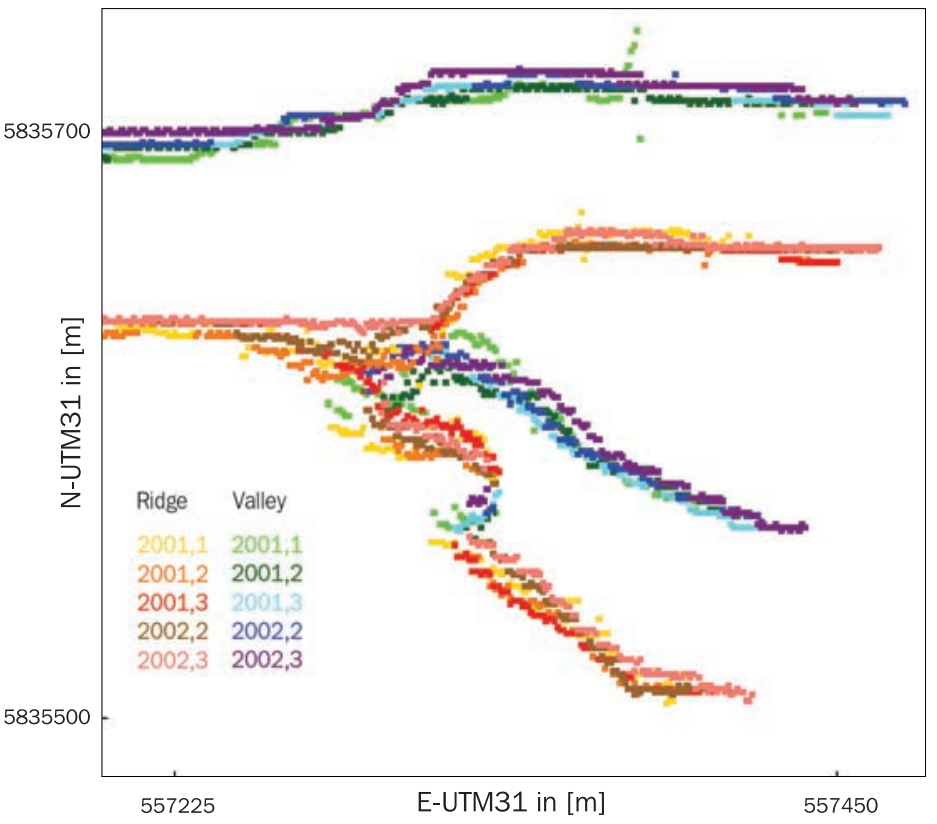

Figure 11. Two-dimensional crest and trough lines with the geostatistical method (a) for the entire Egmond area of one epoch and (b) for a detail of a bifurcation in the northeast corner for all epochs.

automated methods in this paper, as well as agreement with manual results, strengthens our method's credibility.

[57] For the Rotterdam site, relevant records of characteristics of sand waves and in some cases megaripples are based on manual measurements from vertical echo sounding profiles from 1935-1938 and 1967-1969 [Terwindt, 1971] and 1982 to 1985 [Tobias, 1989] and nautical charts of the same periods, and on automated measurements on recent data 1995-2002 [Knaapen, 2005] and 1990s to 2004 [Dorst et al., 2006] (Tables 4 and 5). Our average sand wavelengths are smaller than the average lengths in the literature, but all variables ( $\mathrm{L}, \mathrm{H}$, orientation and migration) fall largely within published ranges for nearby sites. Thus, if the comparison to highly spatially and temporally variable bed forms in the literature is considered to be valid, our results for sand waves seem to refine results in comparison to older methods. It must be noted that most findings in the existing literature are based upon data that are of significantly less horizontal resolution, that sites are at some distance to our site and that local conditions may have changed in the harbor approach zone. Compared to Knaapen [2005], our sand waves are much higher, which (a)

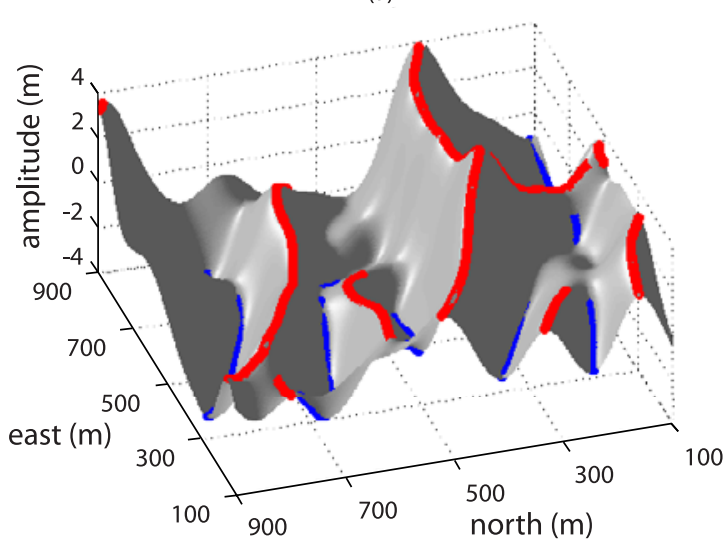

(b)

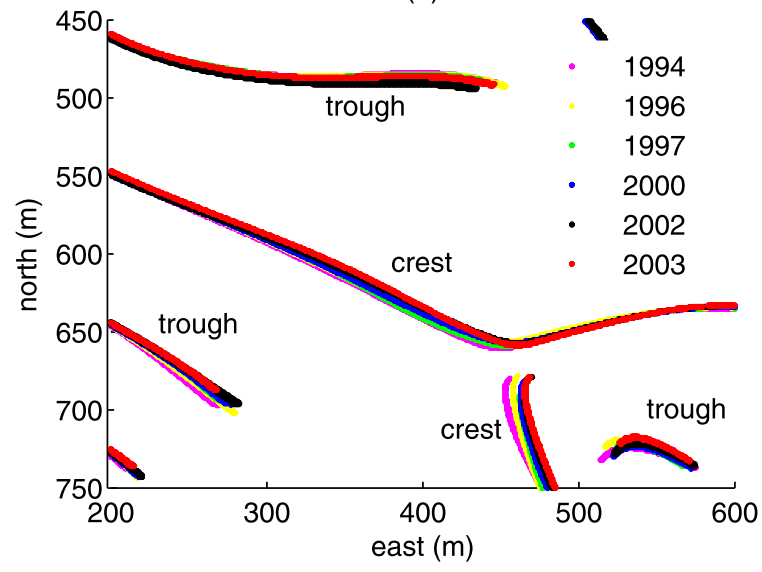

Figure 12. (a) Three-dimensional crest and trough lines with the Fourier method for the entire Rotterdam area for one epoch and (b) plan view of a detail of a bifurcation for six epochs. 
Table 4. Sand Wave Characteristics for Rotterdam From the Literature

\begin{tabular}{|c|c|c|c|c|c|c|c|c|c|c|c|}
\hline & \multicolumn{4}{|c|}{$\mathrm{L}_{\mathrm{sw}}(\mathrm{m})$} & \multicolumn{4}{|c|}{$\mathrm{H}_{\mathrm{sw}}(\mathrm{m})$} & \multirow[b]{2}{*}{ Orientation (deg): } & \multirow[b]{2}{*}{ Mrate $(\mathrm{m} / \mathrm{a})$ : Mean } & \multirow[b]{2}{*}{ Distance $(\mathrm{km})$} \\
\hline & Mean & SD & Min & Max & Mean & SD & Min & Max & & & \\
\hline Terwindt [1971] (site 9) & 288 & - & - & - & 7.7 & - & - & - & 140 & - & $3 \mathrm{NE}$ \\
\hline Tobias [1989] (Euro-channel) & 333 & 167 & 115 & 550 & 6.3 & 2.3 & 2.5 & 9.8 & 110 & 2 to $\mathrm{SW}$ & $5.5 \mathrm{SW}$ \\
\hline Tobias [1989] (W of E-platform) & 195 & 94 & 88 & 448 & 4.7 & 1.6 & 2.2 & 8.8 & 116 & 2 to $\mathrm{SW}$ & $6-6.7 \mathrm{E}$ \\
\hline Knaapen [2005] (Approach Channel 1) & 230.3 & - & - & - & 2.5 & - & - & - & 135 & 0.2 to $\mathrm{NE}$ & 2.6 SE \\
\hline Dorst et al. [2006] (sites A-K or J) & - & - & 257 & 988 & - & - & 0.2 & 4.6 & - & $0-2.7(\mathrm{~J}: 0)$ & $\mathrm{J}: 20 \mathrm{~W}$ \\
\hline
\end{tabular}

may be explained by high local variability apparent from the literature, and our migration rates, in contrast with the Egmond case, are higher in the Rotterdam case. Dorst et al. [2006] found static sand waves in the case (site J) closest to our site.

[58] In contrast, the variability in sizes of megaripples, obtained with the two methods in this paper, is larger than those reported in the literature (Table 5). We explain this by the increase in range of megaripple sizes now that all individual megaripples are counted, as opposed to assumed representative averages in the manual methods or methods using low-resolution data.

[59] Automated methods for the quantitative analysis of bathymetric surveys are in a pioneer phase, certainly for mobility analyses. With the two methods presented in this paper, we add to the filtering method of Knaapen [2005] because here we provide for the separation of compound bed forms, which can subsequently be analyzed individually, and to the method of Dorst et al. [2006], because here we reach the level of megaripples in the direct (nonidealized) analysis of empirical data.

[60] The 2-D calculation of crest and trough locations in time for both the Rotterdam and Egmond time series and in both methods, indicate that sand waves behave most dynamically near bifurcation points. Therefore, future research should not only focus on possible movement of sand wavefields as a whole, as done by, e.g., Knaapen [2005] and Dorst et al. [2006], but should also take into account the lateral behavior of crests and troughs, by analyzing for example the process of bifurcation.

[61] As in many automated analysis methods, several subjective choices have to be made in the tuning of both the Kriging and Fourier methods to obtain the desired result. Note that in the results section, no value for the accuracy of the found bed form orientations is provided for in the Kriging case, but the robustness of determining the bed form orientation via the variogram analysis can be tested as described in section 2.2.6. In terms of sensitivity, if the variability in different directions is strongly varying, as in Figure 2, the actual choice of which variogram model to use, does in general not affect the found value for the bed form orientation. As stated before, the choice of the variogram model and associated variogram parameters (nugget, range and sill) strongly affects the bed form decomposition results. Whereas the decomposed signal in the Fourier method is discrete (with a finite number of frequencies below the chosen cutoff frequency), the decomposition in the Kriging method depends continuously on the variogram parameters.

[62] Sensitivity tests for the Fourier method point out that changing the cutoff frequencies in the 1-D Fourier method results in a visual difference of the approximation of the input signal, but has only a small effect on the morphologic parameters of sand waves. For example, in the Egmond case, changing the cutoff frequency from 28 to 62 frequencies gave a visually improved approximation, but resulted in merely a $0.7 \mathrm{~m}$ difference for the average sand wavelength and $0.06 \mathrm{~m}$ for the average height. This insensitivity is because the cutoff frequencies are chosen in a low-power domain, in which frequencies have only a small contribution to the separated grouped components of dominant frequencies that represent bed forms of different scales. For the migration rates, differences are higher, in this example from $1.7 \mathrm{~m} / \mathrm{a}$ to $2.9 \mathrm{~m} / \mathrm{a}$, because of a jump in one of the preferred automated CT locations in only 1 of the epochs. In the Fourier method we tuned the cutoff frequencies such, that crests of all regular sand waves were optimally approximated, thereby increasing the uncertainty of one bifurcated crest (which was removed as outlier).

[63] The efficiency of quantitative analysis methods becomes important when working with large data sets, such as MBES. Given $N$ observations, the 2-D Fast Fourier Transform needs $\mathrm{O}\left(N \log _{2} N\right)$ calculations and is therewith much faster than the geostatistical method, which needs $\mathrm{O}\left(N^{3}\right)$ calculations in the worst case. Note, however, that methods for computational simplification of the Kriging approach are under development [e.g., Cressie and Johannesson, 2006]. Tuning of the input parameters for filtering the 2-D surfaces requires some a priori insight in both methods, but is more complicated in the Fourier method than in the geostatistical method. Tuning of the input parameters for smoothing 1-D profiles is in the Fourier method a simple case of choosing cutoff wavelengths.

[64] In terms of flexibility, the geostatistical method has a higher level of acceptance of input data anomalies. For example, the geostatistical method handles input grids with data gaps, whereas the Fourier method does not deal well with these. Gaps in the grids are easily filled in grid fill applications of existing interpolation software. Purely in terms of separation, the Fourier method allows for custom-

Table 5. Megaripple Characteristics for Rotterdam From the Literature

\begin{tabular}{|c|c|c|c|c|c|c|c|c|c|}
\hline & \multicolumn{4}{|c|}{$\mathrm{L}_{\mathrm{mg}}(\mathrm{m})$} & \multicolumn{4}{|c|}{$\mathrm{H}_{\mathrm{mg}}(\mathrm{m})$} & \multirow[b]{2}{*}{ Distance $(\mathrm{km})$} \\
\hline & Mean & $\mathrm{SD}$ & Min & Max & Mean & SD & Min & Max & \\
\hline Terwindt $[1971]$ (joint sites) & - & - & - & - & $0.3-2$ & - & - & - & unknown \\
\hline Tobias [1989] (E-platform) & 12.8 & 4.1 & 7 & 22 & 0.48 & 0.23 & 0.2 & 1.2 & $17 \mathrm{ENE}$ \\
\hline
\end{tabular}


controlled deselection of certain CT points, which makes tuning of the input parameters more flexible and may thereby reach an optimal approximation of the sand wave heights without interfering with the megaripple signal. Underestimation of heights has an effect on slope calculations. The geostatistical method deals better with nonperiodic features, such as one broad crest, for example at bifurcation points, in a series of regular sand waves.

[65] Both methods can be extended to an analysis of any number of bed form types by increasing the number of scaled analyses in the geostatistical method and by increasing the number of truncations in the Fourier method. First experimental results [Pluymaekers et al., 2007] indicate that methods for bed form decomposition can be combined with bed form parameter-based segmentation of nonhomogeneous domains. Also, other important bed form characteristics that were not presented in this paper, such as the asymmetry, were determined automatically within the methods presented. In order to serve physical morphodynamic models, parameter definitions could easily be adjusted to custom-defined parameters. Furthermore, through the use of different definitions [Rana, 2006], the Fourier method allows for the automated detection of other characteristic bed form points, such as the "brink point" and "toe point" [e.g., Allen, 1968, p.62] in addition to crest, trough and inflection points (see Figure 1). Brink points normally indicate the points where flow separation occurs, but at low-angle marine sand waves, flow separation does not occur [Best, 2005]. Nevertheless, sand waves do have these points that characterize their morphology. Therefore, we would like to add to the discussion whether brink points should be taken into account in sand wave mobility studies, for which, until now, mainly crest points have been used. We have not tested whether brink and toe points could be identified on megaripples.

\section{Conclusions and Wider Implications}

[66] Two newly extended methods, a geostatistical and Fourier method, for the separation of 1-D and 2-D compound bathymetric signals are compared and evaluated, and are demonstrated to be successful in analyzing bed form types of different spatial scales. Results from two case studies in the North Sea show that the geostatistical method underestimates sand wave heights only slightly more than the Fourier method, because of a stronger smoothing of the sand wave signal, due to which sand wave crests appear in the residual 1-D and 2-D megaripple signals. This anomaly may be reduced by the different tuning of input parameters, the choice of which is prescribed by the research aim of the analysis, or by incorporating a variable horizontal resolution in future work.

[67] With the two methods presented in this paper, we improved the analytical possibilities and accuracy of existing filtering methods, because here we provide for the separation of compound bed forms into any level of bed form types, down to the level of megaripples, which each can subsequently be quantified individually in a direct (nonidealized) analysis of empirical data.

[68] Both separation methods allow for the automated determination of geometric and dynamic parameters of individual bed forms. The close agreement of the results of both methods, each using an independent algorithm, and correspondence to manual results make their credibility convincing. Between methods, sand wavelengths and heights differ only $0.42-8.2 \%$. For megaripples this difference is $32-65 \%$, but individual megaripples are well recognizable in shape. Migration rates of sand waves differ $7.0-11.2 \%$ between methods, thereby refining previous estimates.

[69] Analyses performed with these methods contribute to the explanation of the dynamics of compound bed forms. These methods were developed for future investigations of the interference of bed forms, an entirely new research question, whereby sand banks, long bed waves [Knaapen et al., 2001], sand waves and megaripples need to be separated. The automated determination of bed form parameters is a relatively objective approach compared to previous methods. It can deal with large amounts of bed forms efficiently, thereby forming a means to the production of empirical morphodynamic data for the validation of theoretical models as well as for the applied use of compiling morphodynamic maps of continental shelves for offshore developers and for the management of coastal, marine and estuary environments. The additional identification of brink and toe points may also make this method valuable for the analysis of river dunes.

[70] Acknowledgments. Data were collected by the North Sea Directorate, Dutch Public Works and Water Management (DNZ-RWS), aboard the Ms. Arca. Simon Bicknese (RWS) is acknowledged for providing validated digital multibeam data and grids. The in-house interpolation software used in the Fourier method was developed by Jan Brouwer (TNO). Part of this work was done during the TNO projects Dynamics and Sediment Classification of the North Seabed (DYSC) and Inventory of Habitats of the North Seabed (INHABIT). This work contributes to the Delft Cluster project "Sustainable Development North Sea and Coastal Zone" and to the EU project Mapping European Seabed Habitats (MESH, http://www.searchmesh.net) and received European Regional Development Funding through the INTERREG III B Community Initiative (http:// www.nweurope.org). This paper was much improved thanks to the comments of Déborah Idier and two anonymous reviewers.

\section{References}

Allen, J. R. L. (1968), Current Ripples, Their Relation to Patterns of Water and Sediment Motion, 433 pp., North-Holland, Amsterdam.

Besio, G., P. Blondeaux, M. Brocchini, and G. Vittori (2003), Migrating sand waves, Ocean Dyn., 53, 232-238, doi:10.1007/s10236-1000310043-X.

Besio, G., P. Blondeaux, M. Brocchini, and G. Vittori (2004), On the modeling of sand wave migration, J. Geophys. Res., 109, C04018, doi:10.1029/2002JC001622.

Besio, G., P. Blondeaux, and G. Vittori (2006), On the formation of sand waves and sand banks, J. Fluid Mech., 557, 1-27, doi:10.1017/ S0022112006009256.

Best, J. (2005), The fluid dynamics of river dunes: A review and some future research directions, J. Geophys. Res., 110, F04S02, doi:10.1029/ 2004JF000218.

Bottelier, P., C. Briese, N. Hennis, R. Lindenbergh, and N. Pfeifer (2005), Distinguishing features from outliers in automatic Kriging-based filtering of MBES data: A comparative study, in Geostatistics for Environmental Applications, edited by P. Renard, H. Demougeot-Renard, and R. Froidevaux, pp. 403-414, Springer, Berlin.

Cazals, F., J.-C. Faugère, M. Pouget, and F. Rouillier (2005), The implicit structure of ridges of a smooth parametric surface, Comput. Aided Geometric Design, 23, 582-598, doi:10.1016/j.cagd.2006.04.002.

Cherlet, J., G. Besio, P. Blondeaux, V. van Lancker, E. Verfaillie, and G. Vittori (2007), Modeling sand wave characteristics on the Belgian Continental Shelf and in the Calais-Dover Strait, J. Geophys. Res., 112, C06002, doi:10.1029/2007JC004089.

Cressie, N., and G. Johannesson (2006), Spatial prediction of massive datasets, paper presented at Elizabeth and Frederick White Conference, Aust. Acad. of Sci., Canberra, A. C. T. 
Cullen, R. (2005), Sandwave migration-Seabed mobility and shallowwater swathe sounding, Hydro Int., 9, 6-9.

Dorst, L. L. (2004), Survey plan improvement by detecting sea floor dynamics in archived echo sounder survey, Int. Hydrogr. Rev., 5, 49-63.

Dorst, L. L., P. C. Roos, and S. J. M. H. Hulscher (2006), Estimation of sand wave dynamics in the southern North Sea, in Coastal Engineering 2006: Proceedings of the 30th International Conference, pp. 2630-2642, World Sci., Hackensack, N. J.

Elias, E. P. L., M. J. F. Stive, J. F. Bonekamp, and J. Cleveringa (2003), Tidal inlet dynamics in response to human intervention, Coastal Eng. J., 45, 629-658, doi:10.1142/S0578563403000932.

FitzGerald, D. M., , and J. Knight (Eds.) (2005), High Resolution Morphodynamics and Sedimentary Evolution of Estuaries, 364 pp., Springer, Dordrecht, Netherlands.

Goovaerts, P. (1997), Geostatistics for Natural Resources Evaluation, Oxford Univ. Press, Oxford, U. K.

Gray, A. (1997), Modern Differential Geometry of Curves and Surfaces With Mathematica, 2nd ed., CRC Press, Boca Raton, Fla.

Heiskanen, W. A., and H. Moritz (1967), Physical Geodesy, W.H. Freeman, San Francisco, Calif.

Hulscher, S. J. M. H. (1996), Tidal-induced large-scale regular bed form patterns in a three-dimensional shallow water model, J. Geophys. Res., 101, 20,727-20,744.

Hulscher, S. J. M. H., and G. M. Van den Brink (2001), Comparison between predicted and observed sand waves and sand banks in the North Sea, J. Geophys. Res., 106, 9327-9338, doi:10.1029/2001JC900003.

Idier, D., A. Ehrhold, and T. Garlan (2002), Morphodynamics of an undersea sandwave of the Dover Straits, C.R. Geosci., 334, 1079-1085, doi:10.1016/S1631-0713(02)01852-7.

Idier, D., D. Astruc, and S. J. M. H. Hulscher (2004), Influence of bed roughness on dune and megaripple generation, Geophys. Res. Lett., 31, L13214, doi:10.1029/2004GL019969.

Knaapen, M. A. F. (2005), Sandwave migration predictor based on shape information, J. Geophys. Res., 110, F04S11, doi:10.1029/2004JF000195.

Knaapen, M. A. F., S. J. M. H. Hulscher, H. J. de Vriend, and A. Stolk (2001), A new type of sea bed waves, Geophys. Res. Lett., 28, $1323-$ 1326, doi:10.1029/2000GL012007.

Knaapen, M. A. F., C. N. Van Bergen Henegouw, and Y. Y. Hu (2004), Qualitifying bed form migration using multi-beam sonar, Civ. Eng. and Manage. Res. Rep., 2004-004/WEM-007, 16 pp., Univ. of Twente, Enschede, Netherlands.

Kraus, K., and N. Pfeifer (1998), Determination of terrain models in wooded areas with airborne laser scanner data, ISPRS J. Photogramm. Remote Sens., 53, 193-203.

Lanckneus, J., and G. De Moor (1991), Present-day evolution of sand waves on a sandy shelf bank, Oceanol. Acta, 11, 123-127.

Lindenbergh, R. C. (2004), Parameter estimation and deformation analysis of sand waves and mega ripples, paper presented at Second International Conference on Marine Sandwave and River Dune Dynamics (MARID2004), Univ. of Twente, Enschede, Netherlands.

Lurton, X. (2002), An Introduction to Underwater Acoustics, Springer, London.

Morelissen, R., S. J. M. H. Hulscher, M. A. F. Knaapen, A. A. Németh, and R. Bijker (2003), Mathematical modelling of sand wave migration and the interaction with pipelines, Coastal Eng., 48, 197-209, doi:10.1016/ S0378-3839(03)00028-0.

Mulla, D. J. (1988), Using geostatistics and spectral analysis to study spatial patterns in the topography of southeastern Washington State, U.S.A. Earth Surf. Processes Landforms, 13, 389-405, doi:10.1002/ esp.3290130505.

Németh, A. A. (2003), Modelling offshore sand waves, Ph.D. thesis, Univ. of Twente, Enschede, Netherlands.

Németh, A. A., S. J. M. H. Hulscher, and H. J. de Vriend (2002), Modelling sand wave migration in shallow shelf seas, Cont. Shelf Res., 22, $2795-$ 2806, doi:10.1016/S0278-4343(02)00127-9.
Németh, A. A., S. J. M. H. Hulscher, and R. M. J. Van Damme (2007), Modelling offshore sand wave evolution, Cont. Shelf Res., 27, 713-728, doi:10.1016/j.csr.2006.11.010

Oppenheim, A. V., A. S. Willsky, and S. Hamid (1997), Signals and Systems, 2nd ed., 957 pp., Prentice-Hall, Upper Saddle River, N. J.

Pluymaekers, S., R. Lindenbergh, D. Simons, and J. de Ronde (2007), A deformation analysis of a dynamic estuary using two-weekly MBES surveying, paper presented at Oceans '07, Inst. of Electr. and Electron. Eng., Aberdeen, U. K.

Press, W. H., S. A. Teukolsky, W. T. Vetterling, and B. P. Flannery (2002) Numerical Recipes in C++: The Art of Scientific Computing, 2 nd ed., 1002 pp., Cambridge Univ. Press, Cambridge, U. K

Rana, S. (2006), Use of plan curvature variations for the identification of ridges and channels on DEM, in Progress in Spatial Data Handling, edited by A. Riedl, W. Kainz, and G. Elmes, pp. 789-804, Springer, Berlin.

Santoro, V. C., E. Amore, L. Cavallaro, and M. De Lauro (2004), Evolution of sand waves in the Messina Strait, Italy, Ocean Dyn., 54, 392-398, doi:10.1007/s10236-003-0087-y.

Sithole, G., and G. Vosselman (2004), Experimental comparison of filter algorithms for bare-Earth extraction from airborne laser scanning point clouds, ISPRS J. Photogramm. Remote Sens., 59(1-2), 85-101.

Soulsby, R. L. (1997), Dynamics of Marine Sands, 249 pp., Thomas Telford, London.

Stam, J. (1994), Process-based modeling of aeolian bedforms, Ph.D. thesis, Delft Univ. of Technology, Delft, Netherlands.

Terwindt, J. H. J. (1971), Sand waves in the Southern Bight of the North Sea, Mar. Geol., 10, 51-67, doi:10.1016/0025-3227(71)90076-4.

Tobias, F. C. (1989), Morphology of sandwaves in relation to current, sediment and wave data along the Eurogeul, North Sea, Rep. GEOPRO 1989.01, 60 pp., Inst. of Geogr. Res., Univ. of Utrecht, Utrecht, Netherlands.

Van de Meene, J. W. H. (1994), The shoreface-connected ridges along the central Dutch coast, Ph.D. thesis, Univ. of Utrecht, Utrecht, Netherlands.

Van der Veen, H. H., S. J. M. H. Hulscher, and M. A. F. Knaapen (2006), Grain size dependency in the occurrence of sand waves, Ocean Dyn., 56, 228-234, doi:10.1007/s10236-005-0049-7.

Van Dijk, T. A. G. P. (2002), Geometry and patterns of bedforms in a coastal and shallow marine setting, North Sea, TNO Rep. NITG 02230- $A$, Neth. Inst. of Appl. Geosci. TNO, Utrecht, Netherlands.

Van Dijk, T. A. G. P., and M. G. Kleinhans (2005), Processes controlling the dynamics of compound sand waves in the North Sea, Netherlands, J. Geophys. Res., 110, F04S10, doi:10.1029/2004JF000173.

Van Dijk, T. A. G. P., P. J. P. Egberts, J. H. Brouwer, and S. Van Heteren (2006), The mobility of sand waves: An analysis of the behaviour and interference of bedforms from empirical data, paper presented at 8 th Dutch Congress on Geosciences, Ned. Organ. Voor Wet. Onderz., Veldhoven, Netherlands.

Wackernagel, H. (2003), Multivariate Statistics, 3rd ed., Springer, Berlin.

Wever, T. F., and I. H. Stender (2000), Strategies for and results from the investigation of migrating bedforms in the German Bight, paper presented at Marine Sandwave Dynamics, Univ. of Lille, Lille, France.

Wüst, J. (2004), Data-driven probabilistic predictions of bathymetry, paper presented at Second International Conference on MARINE Sandwave and River Dune Dynamics, Univ. of Twente, Enschede, Netherlands.

P. J. P. Egberts, Geological Survey of the Netherlands, TNO Built Environment and Geosciences, P.O. Box 80015, NL-3508 TA Utrecht, Netherlands. (paul.egberts@tno.nl)

R. C. Lindenbergh, Delft Institute of Earth Observation and Space Systems, Delft University of Technology, P.O. Box 5058 NL-2600 GB, Delft, Netherlands. (r.c.lindenbergh@tudelft.nl)

T. A. G. P. van Dijk (corresponding author), Deltares, P.O. Box 85467 , NL-3508 AL Utrecht, Netherlands. (thaienne.vandijk@tno.nl) 